\title{
PRODUCCIONES METALÚRGICAS EN EL NORDESTE DE LA PENÍNSULA IBÉRICA DURANTE EL III MILENIO CAL. AC: EL TALLER DE LA BAUMA DEL SERRAT DEL PONT (TORTELLÀ, GIRONA)
}

\author{
METALLURGICAL PRODUCTION FROM THE \\ NORTH-EAST OF THE IBERIAN PENINSULA \\ DURING III MILLENNIUM CAL. BC: \\ THE BAUMA DEL SERRAT DEL PONT \\ (TORTELLÀ, GIRONA) WORKSHOP
}

\author{
GABRIEL ALCALDE (*) \\ MIQUEL MOLIST $(* *)$ \\ IGNACIO MONTERO $(* * *)$ \\ LLORENÇ PLANAGUMÀ (****) \\ MARÍA SÃ̃̃A $(* *)$ \\ Y ASSUMPCIÓ TOLEDO $(* * * * *)$
}

\section{RESUMEN}

Se presentan los resultados de la excavación en los niveles del III milenio cal. AC del pequeño abrigo rocoso de la Bauma del Serrat del Pont. El yacimiento fue ocupado por un grupo pequeño que organizó el espacio interno con una estructura de material perecedero, excepto en el nivel II.5. Algunos datos indican que las ocupaciones pudieron tener un carácter estacional. Los estudios multidisciplinares reconstruyen un aprovechamiento diversificado de recursos locales, entre los que se integran los dedicados a las tareas metalúrgicas. Se documentan aleaciones intencionadas de bronce de gran antiguedad, el empleo de vasijas horno con o sin decoración campaniforme, y toberas de arcilla.

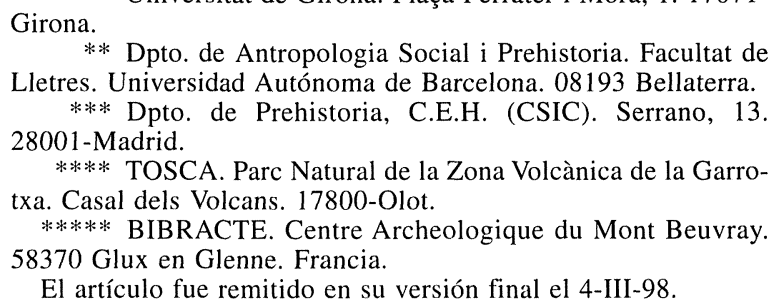
Girona.

** Dpto. de Antropologia Social i Prehistoria. Facultat de Lletres. Universidad Autónoma de Barcelona. 08193 Bellaterra. *** Dpto. de Prehistoria, C.E.H. (CSIC). Serrano, 13. 28001-Madrid.

**** TOSCA. Parc Natural de la Zona Volcànica de la Garrotxa. Casal dels Volcans. 17800-Olot.

****** BIBRACTE. Centre Archeologique du Mont Beuvray. 58370 Glux en Glenne. Francia.

El artículo fue remitido en su versión final el 4-III-98.

* Universitat de Girona. Plaça Ferrater i Mora, 1. 17071

\begin{abstract}
We examine the third millennium cal. BC levels fro-.. the small rockshelter of Bauma del Serrat del Pont. The site was settled by a small group, building a perishable structure except in the II.5 level. Some evidence suggests a seasonal occupation of the site. Multidisciplinary research shows a broad spectrum of local resources involved in the dairy life of this people, including those related to metallurgical activity. We find very old tin alloys, plain or bell beaker decorated pot-furnaces (used to smelt copper ores) and clay tuyeres.
\end{abstract}

Palabras clave: Cataluña. Calcolítico. Campaniforme. Metalurgia. Vasija-horno. Tobera. Mineral de cobre. Aleación con estaño. Abrigo.

Key words: Catalonia. Chalcolithic. Bell beaker. Metallurgy. Pot-furnace. Tuyeres. Copper ore. Tin alloy. Rockshelter.

El presente trabajo se enmarca en el proyecto Actuació arqueològica a la Bauma del Serrat del 
Pont (Tortellà-la Garrotxa): estudi crono-estratigràfic i caracterització espacial de les ocupacions en abrics en el món pirinenc i prepirinenc del III al I mil.lenni, iniciado en 1989 (1). Los objetivos iniciales de investigación se centraron, por una parte, en el análisis diacrónico de las ocupaciones en abrigo y cavidades kársticas y, por otra, y con mayor énfasis, en la caracterización del modo de ocupación, incidiendo tanto en los aspectos de tipo socio-económico como en los de carácter etnográfico. La formulación diferenciada de estas dos líneas de trabajo complementarias pretende enfatizar la necesidad de un mejor conocimiento de las ocupaciones humanas en abrigos o cavidades kársticas del Pirineo catalán, superar la mera caracterización tipológica del material (aumentar los puntos en la repartición espacial de determinados tipos), y ampliar a la vez las cuestiones estrictamente estratigráficas que se vienen priorizando en la investigación de este tipo de asentamientos.

De manera particular, se pretende remarcar el interés de una parte de los resultados obtenidos durante el período 1991-1994 en el yacimiento de la Bauma del Serrat del Pont. Dada su especificidad, se ha creído conveniente ofrecer, sobre algunos aspectos, un desarrollo analítico y expositivo más extenso que el contemplado en la publicación monográfica de los mismos (Alcalde et alii, 1997). En este sentido y dado que una parte significativa de la información que se utiliza en este artículo proviene del trabajo interdisciplinar realizado en el marco general del proyecto, por parte de todo el equipo de investigadores/as, remitimos a la consulta de la publicación monográfica en el caso de desear completar la información sobre temas específicos.

\section{BREVE HISTORIA DE LAS INVESTIGACIONES: LA SECUENCIA ESTRATIGRÁFICA}

La Bauma del Serrat del Pont (Fig. 1) es un pequeño abrigo rocoso situado en el NE de Cataluña, en el macizo calcáreo de laAlta Garrotxa (provincia de Girona) y al lado mismo del río Llierca,

(1) La financiación de los trabajos de excavación ha sido realizada por el Servei d'Arqueologia de la Generalitat de Catalunya, mientras que para la realización de diferentes análisis se han recibido complementos económicos del Centre d'Investigacions Arqueològiques de Girona (Museu d'Arqueologia de Catalunya) y del Museu Comarcal de la Garrotxa.

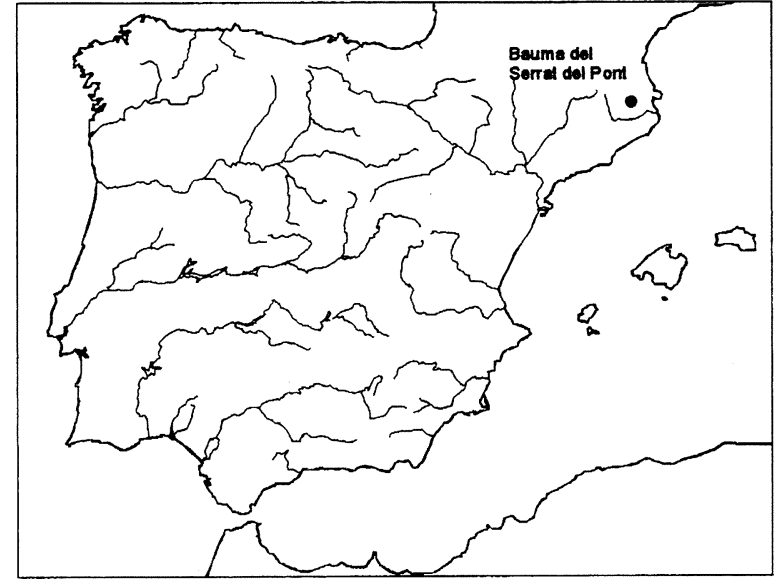

Fig. 1. Localización general del yacimiento.

afluente del Fluvià, a una altura sobre el nivel del mar de 260 m (Lám. I). Los trabajos sistemáticos de excavación han permitido distinguir hasta el momento, gracias a las asociaciones recurrentes

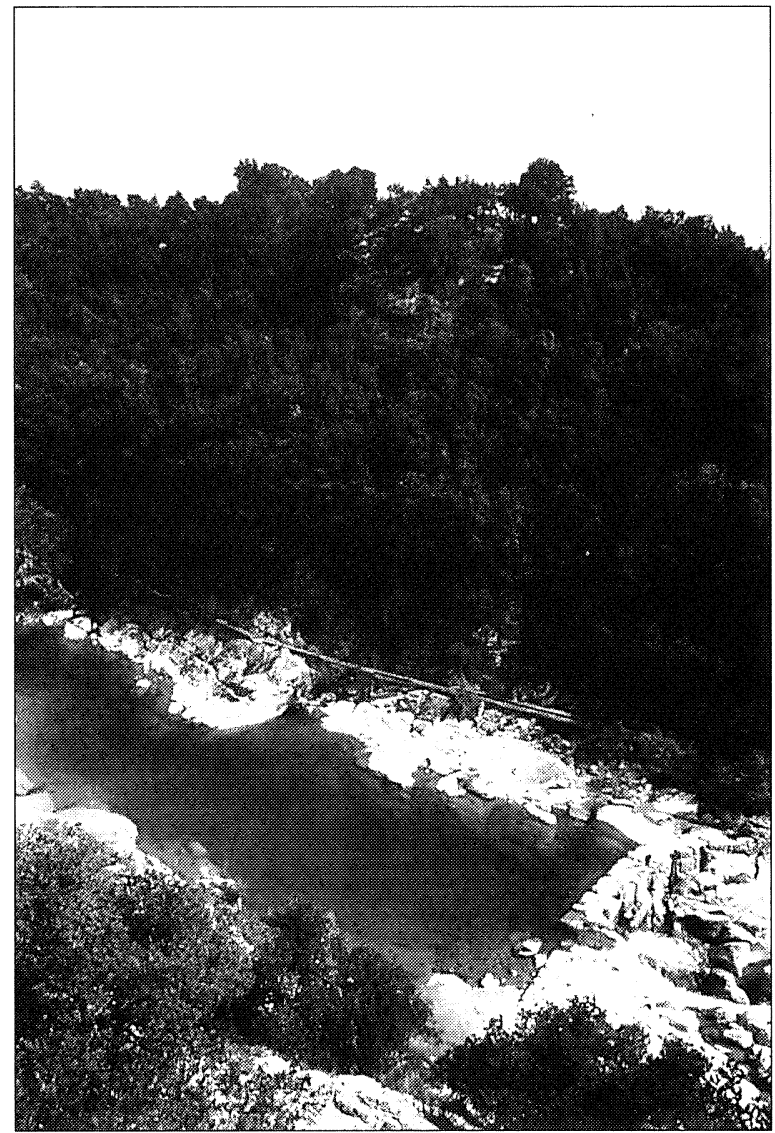

Lam. I. Situación de la Bauma del Serrat del Pont al lado mismo del cauce del río Llierca. 
de restos antrópicos, un total de doce ocupaciones pre y protohistóricas diferenciadas, además de la utilización puntual de este abrigo para diversas finalidades en época romana, medieval y moderna.

En relación a las ocupaciones de época ibérica (niveles arqueológicos II.1.a y II.1.b), se ha documentado una fase principal fechada en los siglos III-II AC y una segunda ocupación de carácter más puntual entre los siglos V-IV AC. De la ocupación principal se ha excavado un muro y diversas estructuras domésticas que, conjuntamente con el resto de material arqueológico, evidencian que en este espacio se había instalado un grupo humano dedicado principalmente a la explotación ganadera y, de manera particular, a la cría de ganado porcino (Alcalde et alii, 1994).

Siguiendo la secuencia estratigráfica, al Bronce Final (niveles arqueológicos II.2.a y II.2.b), corresponden dos fases sucesivas de utilización poco espaciadas temporalmente. Las dataciones absolutas las sitúan hacia el 3160 100 BP (UBAR181). Se ha identificado una cabaña de planta rectangular que delimita un espacio de $54 \mathrm{~m} 2$. La existencia de estructuras de combustión, áreas de procesamiento de vegetales y la distribución general de las diferentes categorías de material arqueológico, evidencian que este espacio se habría destinado principalmente a actividades domésticas y de vida cotidiana de un grupo reducido de personas, que explotaron una gran diversidad de recursos naturales disponibles en el entorno inmediato al asentamiento. Durante este periodo el abrigo cumpliría la función de un asentamiento temporal, probablemente de carácter estacional, vinculado también a la explotación ganadera (Alcalde et alii, 1994).

Los niveles arqueológicos que centran este trabajo son II.3 (Beta-69597: 3840 990 BP), II.4 (Beta-64940: 4100 \pm 90 BP), II.5 (Beta-90622: 4200 \pm 70 BP) y III.1 (Beta-64939: 4020 \pm 100 BP), situados todos en el marco del III milenio cal. AC, constituyendo de esta manera una de las raras secuencias estratigráficas existentes para este intervalo temporal en el nordeste peninsular. El primero de estos niveles corresponde a un tradicional Bronce Antiguo, y los restantes al Calcolítico.

Los trabajos arqueológicos de campo realizados a partir de 1994 han documentado la existencia, como mínimo, de otros cuatro niveles arqueológicos, dos correspondientes al neolítico final, uno al neolítico antiguo y uno al mesolítico, todos ellos en curso de excavación y estudio.
Entrando de manera concreta en las cuestiones específicas que se abordan en este artículo, cabe resaltar que la caracterización socioeconómica de los grupos humanos que habitaron este abrigo durante el III milenio cal. AC constituye una documentación de primer orden en relación al conocimiento de la primeras producciones metalúrgicas del nordeste peninsular. La información aportada hasta el momento por este yacimiento contribuirá, sin duda, a avivar la polémica y la discusión planteada entorno a la significación del vaso campaniforme. La constatación de la producción local de vasos de estilo campaniforme, así como de su utilización como elementos técnicos en el marco del proceso metalúrgico, aparte de novedosa, amplía considerablemente y diversifica el conjunto de datos disponibles hasta el momento en el marco geográfico del nordeste peninsular.

\section{ESTRUCTURACIÓN DEL ESPACIO DURANTE EL III MILENIO cal. AC}

Las cuatro ocupaciones del III milenio cal. AC se caracterizan por la presencia de estructuras domésticas con una utilización del espacio dedicado al desarrollo de las actividades productivas implicadas en la subsistencia y mantenimiento de los grupos humanos que lo habitaban. Sin embargo, la organización de este espacio muestra pautas heterogéneas en relación a la intensidad, funcionalidad y duración de estas ocupaciones. Destaca un cierto grado de especificidad en la ocupación del nivel II.5, interpretada como taller metalúrgico, lo que no excluye la práctica de actividades metalúrgicas en las otras tres ocupaciones.

La singularidad mencionada para el nivel II.5 reside en la ausencia de elementos constructivos propios de estructuras habitacionales, tal y como se documenta en el resto de ocupaciones calcolíticas y de la Edad del Bronce de este abrigo. Las estructuras de habitación consisten en cabañas de planta rectangular, situadas en la parte central del abrigo rocoso natural, construidas principalmente con materiales perecederos, aunque existen ligeras diferencias en las técnicas constructivas de los niveles II.3 y II.4 y la del nivel III.1.

En el nivel II.3 el espacio de habitación estaría delimitado por doce estructuras de sostenimiento de planta circular, excavadas en el subsuelo. Su conformación general permite caracterizarla como una estructura aérea básica y de construc- 
ción simple, resaltando la presencia de un pequeño hogar interior, mientras que un segundo de mayor diámetro se ubica al exterior. De manera análoga, en el nivel II.4, un conjunto de cinco estructuras de sostenimiento distribuidas de manera ordenada permiten precisar la disposición rectangular de los soportes verticales, destacando un elemento que funcionaría como soporte central de la cubierta. En cambio, en el nivel III.1 se ha documentado una organización relativamente más compleja. La estructura de habitación reposa, en este caso, sobre una base que realizaría la función de aislante (empedrado), de tendencia rectangular y construida a partir de bloques de piedra calcárea de reducidas dimensiones, que ocupa una superficie aproximada de $24 \mathrm{~m} 2$. Cinco estructuras de sostenimiento rodean esta plataforma, reforzadas también en su eje central.

El elemento más característico de estas ocupaciones, y particularmente en el nivel II.5, lo constituyen las estructuras de combustión y las áreas adyacentes de vaciado y dispersión de residuos. De diversas configuraciones y contenidos, presentan diferencias cuantitativas y cualitativas significativas, tanto en su situación, como en su utilización. El combustible implicado en su alimentación se ha recogido, en todos los casos, en las inmediaciones del asentamiento. Se ha documentado la utilización de 17 especies de madera diferentes (Fig. 2), pero predominan el roble y boj, no observándose una dinámica diferencial respecto a los criterios de selección y utilización de las mismas.

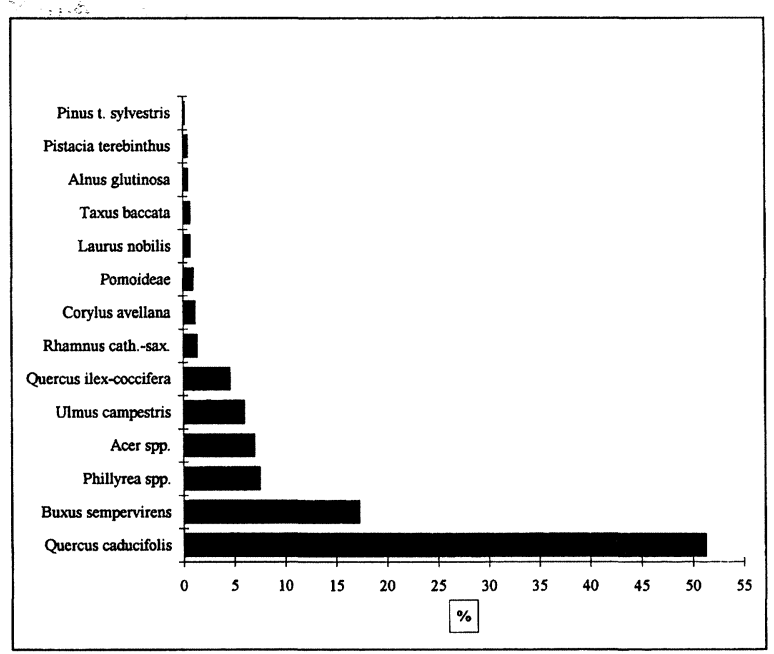

Fig. 2. Análisis antracológicos del nivel III.1.

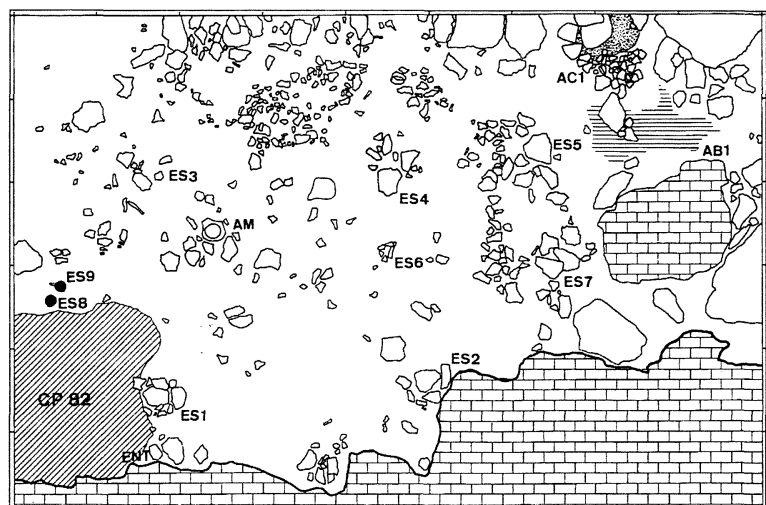

Fig. 3. Planta general del nivel arqueológico II.4.

La ubicación del hogar y áreas de evacuación de los residuos de combustión en el nivel II.4 (Fig. 3), evidencia que los procesos de trabajo relacionados con las mismas se llevarían a cabo en el exterior de la habitación, a diferencia del procesado de materias vegetales, que se realizaría en el interior de la habitación cubierta, tal como indica la concentración significativa de morteros y molinos asociables directamente a estas actividades. La distribución espacial de las diferentes categorías de material arqueológico recuperado muestran una dinámica diferencial en relación al espacio interno/externo de la habitación, concentrándose principalmente en el espacio exterior. Esta misma relación se ha constatado para los niveles II.3 y III.1, si bien durante esta última ocupación el hogar se sitúa en el interior de la habitación construida.

La ocupación del nivel arqueológico II.5 (Fig. 4) presenta un número superior de hogares (tres), todos de características análogas, destacando sus elevadas dimensiones y una fuerte dispersión de

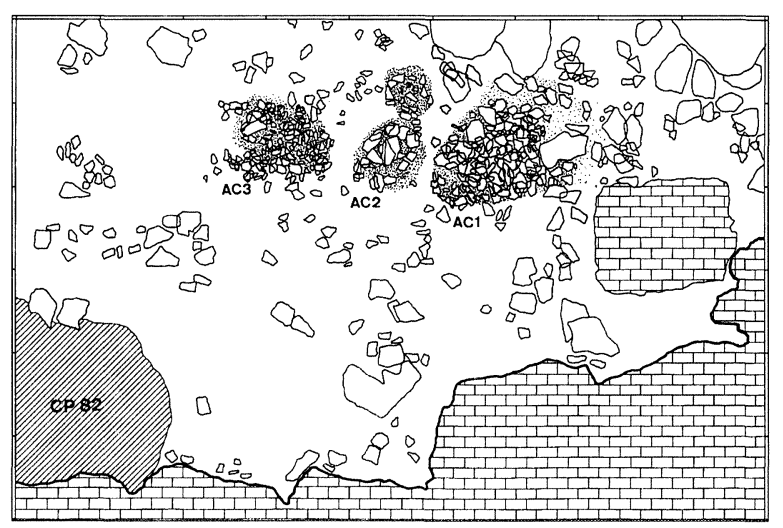

Fig. 4. Planta general del nivel arqueológico II.5. 
residuos de combustión en la práctica totalidad del área excavada. Los hogares están situados fuera de la cornisa del abrigo, hecho que facilitaría probablemente la evacuación del humo. Las estructuras de combustión no presentan en este caso las características de los hogares de uso doméstico descritos anteriormente. Se trata de estructuras de tipo plano, con una ligera depresión donde se acumulan un número relativamente elevado de fragmentos de piedra termo-alterados. Se observa también un cierto grado de diferenciación, respecto a los niveles II.3, II.4 y III.1, en las frecuencias de representación y características técnico-estilísticas de los objetos de ornamentación, instrumentos líticos y materiales cerámicos. Estas características, junto a las mencionadas anteriormente, permiten plantear una utilización diferente de este espacio. Se ha propuesto, en este sentido, una práctica específica de actividades vinculadas a la transformación del metal y producción de objetos de cobre.

\section{LA GESTIÓN DE LOS RECURSOS ANIMALES Y VEGETALES: DIVERSIDAD Y COMPLEMENTARIEDAD DE LAS PRACTICAS SUBSISTENCIALES}

Si bien, la articulación espacial de los diversos elementos arqueológicos registrados para cada ocupación muestra una estructuración diferencial del espacio, el análisis de los restos orgánicos permite proponer una modalidad de gestión de los recursos naturales y domésticos análoga para las tres ocupaciones. Los procesos de trabajo implicados en la adquisición, manutención, manipulación y consumo de los recursos animales y vegetales no varían sustancialmente de una ocupación a otra. En este sentido, las comunidades que habitaban este abrigo durante el intervalo temporal considerado presentan como característica principal la práctica de una estrategia de subsistencia diversificada y no especializada, centrada mayoritariamente en la explotación de los recursos domésticos y complementada por una actividad de caza, pesca y recolección.

Se ha documentado el consumo predominante de cereales domésticos, concretamente Hordeum vulgare y Triticum aestivum/durum, destacando, la total ausencia de leguminosas (Buxó, enAlcalde et alii, 1997) (Tab. 1). La explotación de plantas cultivadas queda evidenciada únicamente por la

\begin{tabular}{|c|c|c|c|c|}
\hline Contextos & GII 27f-28i. & G12 27 hogal & G13 27i & $11327 f$ \\
\hline Volumen en litros & 30 & 20 & 25 & \\
\hline PLANTAS CULTIVADAS (50\%) & & & & \\
\hline Hordeum vulgare & & 1 & & \\
\hline Panicum miliaceum & & & 1 & \\
\hline frags. Hordeum/Triticum & & & & \\
\hline $\begin{array}{l}\text { PLANTAS DE RECOLECCIÓN } \\
(12,5 \%)\end{array}$ & & & & \\
\hline Quercus sp. & & & & 1 \\
\hline MALAS HIERBAS $(25 \%)$ & & & & \\
\hline Trifolium cf. campestre & & & 1 & \\
\hline Trifolium cf. repens & & & 1 & \\
\hline PLANTAS DE RIBERA (12,5\%) & & & & \\
\hline Malva Sylvestris & & & 1 & \\
\hline
\end{tabular}

Tab. 1. Resultados de los análisis carpológicos del nivel II.3.

presencia de restos de cereales. La ausencia de restos asociables directamente a las actividades de trillado puede estar indicando que estas operaciones se desarrollaban en un lugar externo al propio asentamiento. Tampoco se han identificado estructuras de mantenimiento u otros elementos relacionados con el almacenaje de vegetales comestibles.

Dentro del conjunto de plantas silvestres aprovechadas con finalidades alimentarias destaca la recolección de frutos comestibles tales como bellotas, uvas, cerezas, vid silvestre y gerd. Los porcentajes de representación de estas últimas son significativamente más bajos que los de los cereales.

La gestión y explotación de los recursos animales sigue una dinámica análoga a la descrita para los recursos vegetales. Existe una ganadería mixta centrada sobre cuatro especies principales (Tab. 2), buey, cerdo, oveja y cabra, y orientada principalmente a la producción y obtención de alimento cárnico, tal como demuestra la estructura de las poblaciones animales sacrificadas de cada una de las especies, caracterizada por el predominio de machos en edad juvenil, especialmente en el caso de los bóvidos y suidos (Tab. 3). En relación a estos últimos, la abundante presencia de dentición decidual en los niveles II.5 y III.1, ha llevado a proponer su cría y estabulación en el mismo lugar de ocupación (Saña, en Alcalde et alii, 1997).

No se dispone hasta el momento de datos suficientes para incidir de manera concreta en el modo y tipo de ganadería practicada con los ovicaprinos, si bien se ha constatado para cada ocupación la presencia simultánea de oveja y cabra. Se dispone, no obstante, de pequeños datos indirectos que indican una explotación simultánea de algunas de la producciones derivadas potencialmente 


\begin{tabular}{|l|c|c|c|c|c|c|c|c|}
\hline & NR & $\%$ & NR & $\%$ & NR & $\%$ & NR & $\%$ \\
\cline { 2 - 9 } & $I I .3$ & $I I .3$ & $I I .4$ & $I I .4$ & $I I .5$ & $I I .5$ & $I I I . I$ & $I I I .1$ \\
\hline Bos taurus & 39 & 16,5 & 71 & 19,6 & 58 & 17,6 & 101 & 16,5 \\
Bos primigenius & - & - & 1 & 0,2 & - & - & 1 & 0,1 \\
Total BOS & 39 & 16,5 & 72 & 19,9 & 58 & 17,6 & 102 & 16,6 \\
\hline Ovicaprins & 85 & 36,1 & 119 & 32,9 & 101 & 30,6 & 203 & 33,1 \\
Ovis aries & - & - & 16 & 4,4 & 16 & 4,8 & 21 & 3,4 \\
Capra hircus & 5 &, 1 & 15 & 4,1 & 11 & 3,3 & 17 & 2,7 \\
Total ovicaprins & 90 & 38,2 & 150 & 41,5 & 128 & 38,9 & 241 & 39,3 \\
\hline Sus domesticus & 79 & 33,6 & 89 & 24,6 & 107 & 32,5 & 186 & 30,3 \\
Sus scropha & & 1,2 & 7 & 1,9 & 5 & 1,5 & 11 & 1,7 \\
Total SUS & 82 & 34,8 & 96 & 26,5 & 112 & 34 & 197 & 32,1 \\
\hline Equids & 1 & 0,4 & - & - & 1 & 0,3 & 2 & 0,3 \\
\hline Canis familiaris & 3 & 1,2 & 5 & 1,3 & 8 & 2, & 8 & 1,3 \\
\hline Cervus elaphus & 18 & 7,6 & 18 & 4,9 & 12 & 3,6 & 25 & 4 \\
Capra pyrenaica & 1 & 0,4 & 5 & 1,3 & - & - & 12 & 1,9 \\
Capreolus capreolus & - & - & 4 & 1,1 & - & - & 9 & 1,4 \\
\hline Canis lupus & 1 & 0,4 & 1 & 0,2 & - & - & & 0,3 \\
Vulpes vulpes & - & - & 1 & 0,2 & 1 & 0,3 & 1 & 0,1 \\
Meles meles & - & - & 5 & 1,3 & 2 & 0,6 & 2 & 0,3 \\
\hline Lepus sp. & - & - & 2 & 0,5 & - & - & 2 & 0,3 \\
Oryctlagus cunniculus & - & - & - & - & - & - & 1 & 0,1 \\
\hline Aus & - & - & 2 & 0,5 & 7 & 2,1 & 5 & 0,8 \\
Quelonids & - & - & - & - & - & - & 3 & 0,4 \\
\hline TOTAL RD & 235 & & $\mathbf{3 6 1}$ & & $\mathbf{3 2 9}$ & & $\mathbf{6 1 2}$ & \\
\hline MGND & 12 & & 25 & & 25 & & 43 & \\
MNND & 47 & & 119 & & 127 & & 364 & \\
MPND & 9 & & 11 & & 10 & & 42 & \\
\hline TOTAL RND & $\mathbf{6 8}$ & & $\mathbf{1 5 5}$ & & $\mathbf{1 6 2}$ & & $\mathbf{4 4 9}$ & \\
\hline TOTAL RA & $\mathbf{3 0 3}$ & & $\mathbf{5 1 6}$ & & $\mathbf{4 9 1}$ & & $\mathbf{1 . 0 6 1}$ & \\
\hline
\end{tabular}

Tab. 2. Resultados de los análisis arqueozoológicos: MGND = mamífero de talla grande no determinado; $\mathrm{MMND}=$ mamífero de talla mediana no determinado; MPND = mamífero de talla pequeña no determinado; $\mathrm{RD}=$ restos determinados; RND = restos no determinados; RA = restos analizados.

de estas especies, concretamente de la lana para el caso de las ovejas, tal como podría indicar la presencia de una fusayola en el nivel II.5.

Valorando de manera genérica la estrategia ganadera, destaca una explotación equilibrada del trinomio suidos-ovicaprinos-bovinos, aunque son estos últimos los que han proporcionado potencialmente una cantidad superior de biomasa.

En el marco también de la reproducción artificial de especies animales hay que mencionar la presencia de restos de perro y équido, si bien el análisis cualitativo de los mismos no ha proporcionado ningún dato significativo que permita relacionar su explotación directamente con su consumo. Se propone para estas especies la práctica

\begin{tabular}{|l|c|c|c|c|}
\hline & $N M I$ & $N M I$ & $N M I$ & $N M I$ \\
\cline { 2 - 5 } & $I I .3$ & $I I .4$ & $I I .5$ & $I I I . I$ \\
\hline Bos taurus & $1 \mathrm{JU}+1 \mathrm{AD}$ & $1 \mathrm{NEO}+2 \mathrm{JU}+1 \mathrm{AD}$ & $1 \mathrm{JU}+1 \mathrm{AD}$ & $1 \mathrm{JU}+2 \mathrm{AD}$ \\
Bos primigenius & - & - & - & - \\
Total BOS & 2 & 4 & 2 & 3 \\
\hline Ovicaprins & $2 \mathrm{JU}+4 \mathrm{AD}$ & $4 \mathrm{JU}+2 \mathrm{AD}$ & $2 \mathrm{JU}+4 \mathrm{AD}$ & $7 \mathrm{JU}+4 \mathrm{AD}$ \\
Ovis aries & - & $2 \mathrm{AD}$ & $2 \mathrm{AD}$ & $1 \mathrm{JU}+1 \mathrm{AD}$ \\
Capra hircus & $1 \mathrm{AD}$ & $1 \mathrm{AD}$ & $1 \mathrm{AD}$ & $1 \mathrm{JU}+1 \mathrm{AD}$ \\
Total ovicaprins & 6 & 6 & 6 & 11 \\
\hline Sus domesticus & $1 \mathrm{NEO}+\mathrm{JU}+2 \mathrm{AD}$ & $3 \mathrm{JU}+1 \mathrm{AD}$ & $1 \mathrm{NE} 0+4 \mathrm{JU}+1 \mathrm{AD}$ & $2 \mathrm{NE} 0+4 \mathrm{JU}+2 \mathrm{AD}$ \\
Sus scropha & $1 \mathrm{JU}+1 \mathrm{AD}$ & $1 \mathrm{JU}+1 \mathrm{AD}$ & $\mathrm{iJU}$ & $1 \mathrm{JU}+1 \mathrm{AD}$ \\
Total SUS & 8 & 6 & 7 & 10 \\
\hline Equids & - & - & $1 \mathrm{AD}$ & $1 \mathrm{AD}$ \\
\hline Canis familiaris & $\mathrm{AD}$ & $1 \mathrm{JU}+1 \mathrm{AD}$ & $1 \mathrm{AD}$ & $1 \mathrm{AD}$ \\
\hline Cervus elaphus & $1 \mathrm{JU}+2 \mathrm{AD}$ & $2 \mathrm{JU}+1 \mathrm{AD}$ & $1 \mathrm{AD}$ & $1 \mathrm{JU}+1 \mathrm{AD}$ \\
Capra pyrenaica & $1 \mathrm{AD}$ & $1 \mathrm{JU}$ & - & $1 \mathrm{JU}+1 \mathrm{AD}$ \\
Capreolus capreolus & - & $1 \mathrm{JU}$ & - & $1 \mathrm{JU}$ \\
\hline Canis lupus & $1 \mathrm{AD}$ & $1 \mathrm{AD}$ & - & $1 \mathrm{AD}$ \\
Vulpes vulpes & - & $1 \mathrm{AD}$ & $1 \mathrm{AD}$ & $1 \mathrm{AD}$ \\
Meles meles & - & $1 \mathrm{AD}$ & $1 \mathrm{AD}$ & $1 \mathrm{AD}$ \\
\hline Lepus sp. & - & $1 \mathrm{AD}$ & - & $1 \mathrm{AD}$ \\
Oryctlagus cunniculus & - & - & - & $1 \mathrm{AD}$ \\
\hline TOTAL NMI & 22 & 27 & 20 & 36 \\
\hline
\end{tabular}

Tab. 3. Determinación del número mínimo de individuos: $\mathrm{NEO}=$ neonato; $\mathrm{JU}=$ juvenil; $\mathrm{AD}=$ adulto; $\mathrm{M}=$ masculino; $\mathrm{F}=$ femenino.

de una modalidad de gestión orientada al mantenimiento de la comunidad y, de manera particular para los équidos, su utilización como complemento energético en determinados procesos de trabajo $\mathrm{y}$ en tareas de transporte.

La actividad de caza, desarrollada de forma puntual y con menor importancia dentro del conjunto de procesos de trabajo destinados a la consecución de proteínas de origen animal, se dirige principalmente sobre aquellas especies salvajes potencialmente disponibles en los diversos ecosistemas que rodean el asentamiento. Aunque diversificada, predominan los mamíferos de tamaño medio tales como ciervo, jabalí, cabra salvaje y corzo. Complementan esta asociación el lobo, tejón, zorro, liebre, tortuga de agua dulce y algunas aves no determinadas específicamente. No se dispone de pruebas directas del consumo de los carnívoros de tamaño pequeño. Cabe contemplar en este sentido, que la explotación de su piel puede constituir también uno de los objetivos que conlleven a su adquisición y sacrificio. Se ha documentado igualmente la pesca de especies de agua dulce (Tab. 4).

Este amplio grado de diversificación en la explotación de los recursos salvajes se ha constatado 


\begin{tabular}{|c|l|l|l|c|}
\hline Nivel & \multicolumn{1}{|c|}{ Familia } & \multicolumn{1}{|c|}{ Especie } & \multicolumn{1}{|c|}{ P. anatómica } & NR \\
\hline II.3 & Cyprinidae & Barbus sp. & vértebras & 3 \\
\hline II.3 & Cyprinidae & Leuciscus sp. & vértebras & 2 \\
\hline II.3 & Cyprinidae & Lusciscus sp. ? & os farigi inf. & 1 \\
\hline II.3 & Anguillidae & A. anguila & vértebra & 1 \\
\hline II.3 & Indet. & Indet. & vértebras & 2 \\
\hline II.4 & Cyprinidae & Leuciscus sp. & os faringi inf. & 2 \\
\hline II.4 & Cyprinidae & Leuciscus sp. & vértebra & 1 \\
\hline II.4 & Cyprinidae & Rutilus sp. & vértebras & 2 \\
\hline II.5 & Cyprinidae & & os faringi inf. & 1 \\
\hline III.1 & Cyprinidae & Barbus sp. & vértebra & 1 \\
\hline III.1 & Cyprinidae & Leuciscus sp. ? & os faringi inf. & 1 \\
\hline III.1 & Cyprinidae & Rutilus sp. & vértebra & 1 \\
\hline III.1 & Anguillidae & Rutilus sp. & vértebras & 2 \\
\hline III.1 & Indet. & Indet. & vértebra & 2 \\
\hline
\end{tabular}

Tab. 4. Resultados de los análisis ictiológicos.

también, tal como se ha señalado anteriormente, para los recursos vegetales implicados en la obtención de combustible para los hogares (Ros, en Alcalde et alii, 1997), utilizándose para esta finalidad un amplio espectro de maderas procedentes de diferentes ámbitos del paisaje local.

De manera genérica, los datos paleoecológicos (Burjachs y Ros, en Alcalde et alii, 1997) (Fig. 5) muestran un paisaje vegetal en el entorno de este asentamiento bastante diversificado, constituido por todo un mosaico de formaciones vegetales que abarcan desde bosques hasta prados de pasto y campos de cultivo. Se trata, por tanto, de un paisaje modulado por la acción antrópica, en el marco de un clima de tipo mediterráneo, templado y subhúmedo.
Los lugares más húmedos y de umbría estaban formados básicamente por robledales-encinares, complementado por arces, espinos cervales y Rosaceae-Pomoideae-Prunus. Las zonas más abiertas y de sotobosque estarían constituidas, como mínimo, por boj, aladierna, labíernago, brezo y estepas. Al lado de los cursos de agua se encontraban bosques propios de ribera, con avellanos, aliso, sauco, olmo, fresno, e higuera, y con enea en las aguas embalsadas. En las montañas de la región se encontraban pinares y abetosas.

Este entorno se fragmentaría en los lugares adecuados para el cultivo y estaría más o menos aclarado como consecuencia del uso del territorio, de su morfología y del clima, tal como lo indican los taxones heliofilos.

A partir de los datos expuestos, podemos caracterizar a los grupos humanos que habitaron este abrigo como unidades sociales autosufucientes que gestionaban de manera relativamente autónoma los recursos domésticos. Esta consideración no excluye la posibilidad de que los animales sacrificados y cereales consumidos formaran parte de cosechas y rebaños mas amplios, propiedad de una comunidad de base a la cual pertenecían el grupo de personas que se desplazaban temporalmente al valle del Llierca. Esta última posibilidad vendría en parte reforzada por el grado de diversificación de la actividad ganadera y por la gestión equilibrada que se hace de las diferentes especies domésticas, así como por la ausencia de eviden-

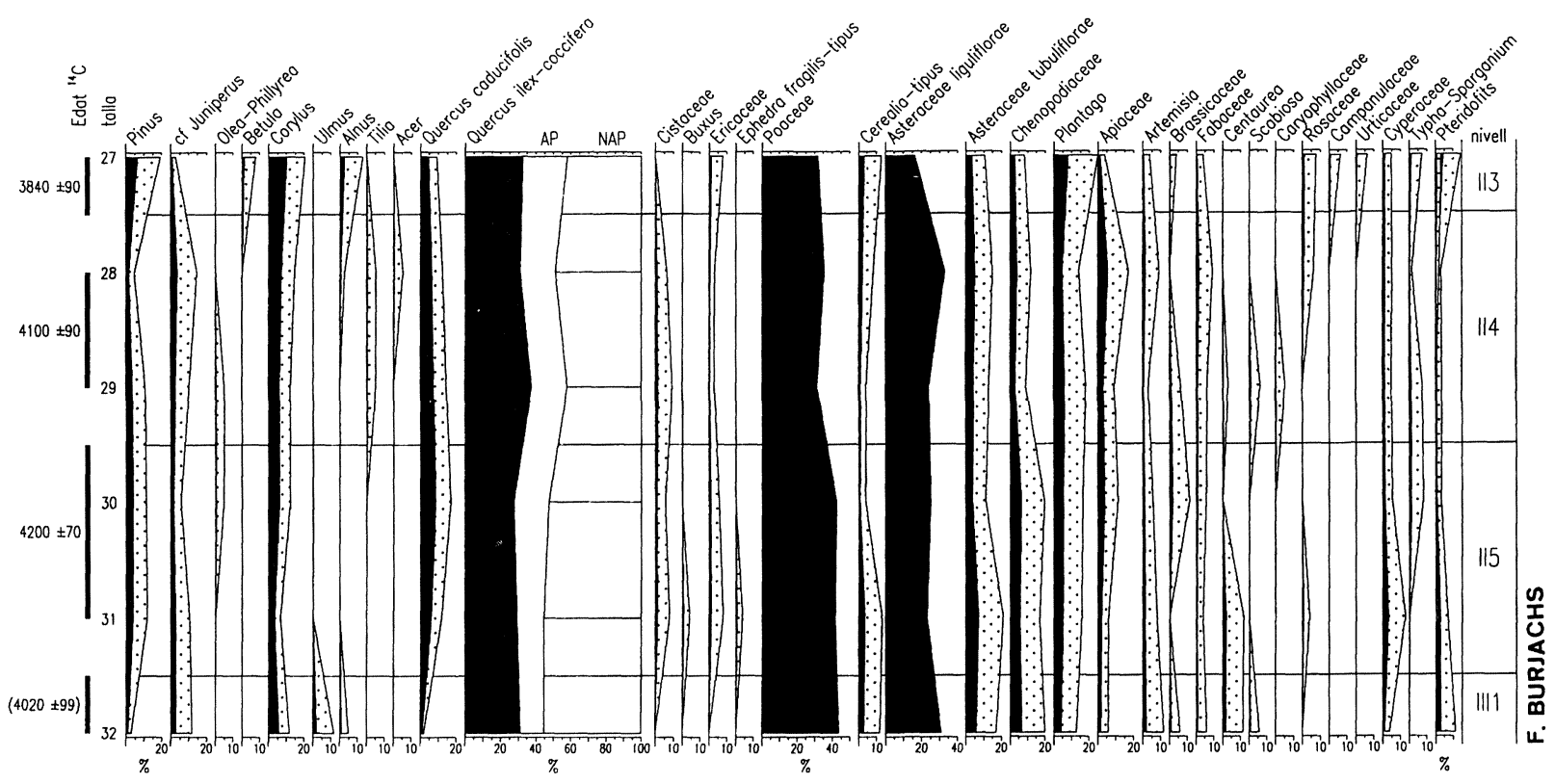

Fig. 5. Resultados de los análisis palinológicos. 
cias directas sobre actividades relacionadas con la cosecha y trillado de cereales. En este sentido, una ganadería diversificada permite minimizar los riesgos inherentes a la propia actividad ganadera. El sacrificio equilibrado de individuos de las diferentes especies reproducidas bajo condiciones artificiales contribuye igualmente a mantener y asegurar la propia reproducción de los rebaños. De aquí se desprende el papel complementario de las actividades de caza, pesca y recolección. La plena consolidación de las técnicas ganaderas queda igualmente apoyada por la explotación de las producciones derivadas en el caso de los recursos animales.

Si bien los datos analizados hasta el momento apuntan hacia que las diversas ocupaciones serian temporalmente cortas, la información sobre el carácter estacional o no de las mismas es más bien escasa. En este sentido, y en relación a la gestión de los recursos animales, los únicos datos disponibles pertenecen a la ocupación del nivel II.4 (Saña, en Alcalde et alii, 1997). En éste, se detecta una elevada homogeneidad en los patrones de sacrificio de las especies animales, tanto salvajes como domésticas, con dominio de juveniles y neonatos (a excepción de los pequeños carnívoros). Estas pautas, a parte de estar relacionas directamente con los criterios de selección derivados de las necesidades de la comunidad, podrían estar indicando la ocupación de este abrigo durante una determinada estación del año, teniendo en cuenta, no obstante, que en el caso de las especies domésticas los ritmos naturales de reproducción pueden verse modificados por la presión y selección humana, especialmente para el caso de los suidos. El posible carácter estacional de la ocupación del nivel II.3 (Buxó, en Alcalde et alii, 1997) se apoyaría en la presencia de especies como malva y bellotas, plantas cuya recolección se vincula preferentemente a la estación otoñal.

\section{LA PRODUCCIÓN DE ARTEFACTOS Y LA IMPORTANCIA DE LAS MATERIAS PRIMAS LOCALES}

La secuencia y el registro material obtenido en la Bauma del Serrat del Pont para el tercer milenio constituye un documento de primer orden para el conocimiento de la evolución diacrónica de las producciones materiales, principalmente las cerámicas, en el nordeste peninsular
El registro cerámico del nivel II.3 (Bronce Antiguo) esta formado por conjuntos de vasos grandes de bordes rectilíneos, de cuerpo globular y base plana, con decoración en el borde o de tipo plástico en el cuerpo, con cordones, a menudo múltiples y dispuestos en forma de guirnaldas, vasitos lisos con doble lengüeta, tazas carenadas y cuencos de tendencia hemiesférica. A nivel de técnicas decorativas, además de una amplia variedad de motivos incisos o impresos, destacan las decoraciones epicampaniformes y algunos motivos solares realizados con la "técnica de boquique" y las aplicaciones irregulares de barro. El análisis cuantitativo de las diferentes técnicas de decoración muestra la importancia significativa de esta última, con porcentajes elevados respecto a los registrados para los niveles calcolíticos, horizonte donde se documenta por vez primera.

En términos generales, estas producciones hallan paralelos en los asentamientos al aire libre recientemente excavados (Institut de Manlleu, Bòvila Madurell, Serra de Clarena), para los cuales se disponen de buenas dataciones radiométricas, lo que permite empezar a considerarlas como representativas del horizonte del Bronce Antiguo del NE Peninsular (Maya, 1992; Boquer et alii, 1995).

La producciones cerámicas de los niveles calcolíticos (II.4, II.5 y III.1) nos permiten estudiar cualitativa y cuantativamente su evolución en la primera mitad del III milenio AC. Si bien a nivel morfológico los datos no son innovadores, constatándose la presencia de vasos globulares de borde rectilineo y cuerpo globular, tazas carenadas, cuencos hemisféricos..., su combinación con las técnicas y motivos decorativos son más significativas. Así, tomando como ejemplo las formas individualizadas, destaca una fuerte presencia (media del $32 \%$ de las formas indivualizadas) de producciones clasificadas como de tradición del neolítico final (veraciense), caracterizada sintéticamente por la presencia de vasos con lengüetas y decoración plástica lisa. Por otra parte, las producciones innovadoras respecto al substrato anterior, caracterizadas por la presencia de decoraciones incisas e impresas, tanto en el cuerpo como en el borde, o combinadas con la plástica (cordones), constituyen también un grupo significativo (media del 8,2\% de las formas individualizadas). Completan el registro las producciones de tipo campaniforme. Para estas últimas la Bauma del Serrat del Pont constituye unos de los pocos yaci- 
mientos del NE peninsular con una presencia elevada y significativa de cerámica campaniforme (media del 23\% de las formas individualizadas).

A nuestro entender, estas cerámicas, de características morfológicas y decorativas similares a las conocidas en la zona del Pirineo Catalán, presentan tres aspectos realmente significativos (Fig. 6): presencia de vasos campaniformes de estilo internacional en contextos no funerarios, presencia conjunta de vasos de diversos estilos (internacional y pirenaico) en el mismo nivel de ocupación y con unas dataciones radiométricas altas, que los sitúa entre las más altas conocidas en el conjunto de la Península Ibérica junto a LaAtayuela (Harrison, 1988) o La cova de les Cendres (Bernabeu, 1989), y finalmente la utilización de vasos campaniformes de estilo pirenaico como vasijas-horno,
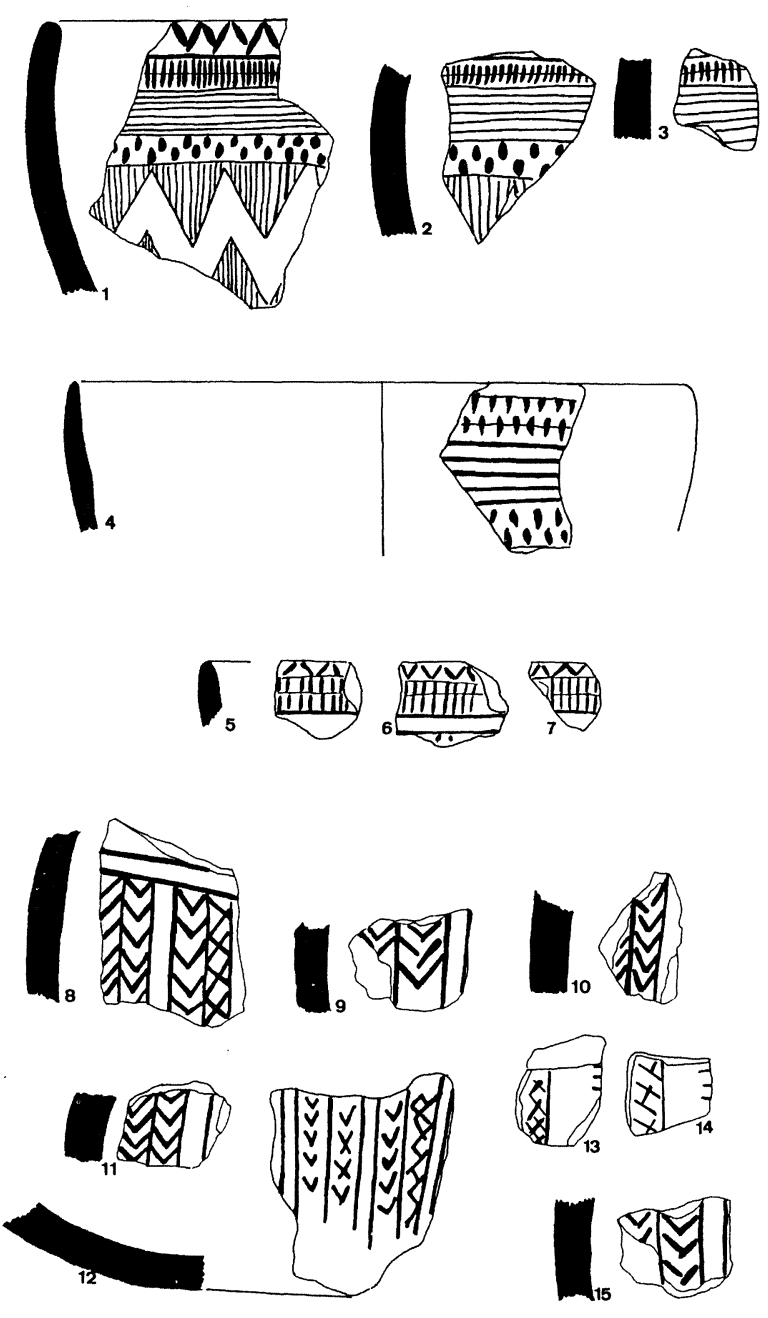

Fig. 6. Decoraciones de cerámicas campaniformes. aspecto que comentaremos en la parte de producciones metalúrgicas (cf. infra).

En el aspecto cronológico, las dataciones asociadas a las decoraciones campaniformes de la Bauma presentan una gran sintonía con zonas o regiones alejadas, como es el caso de las costas Mediterráneas, paralelizables con las recuperadas en la zona del Midi francés (Voruz, 1995) y que se pueden hacer extensivas a otras regiones europeas, como se ha evidenciado recientemente (Castro et alii, 1996), dificultando la interpretación clásica de un foco originario y una posterior dispersión de los productos. Aun así, la proliferación de unas producciones o mejor dicho de unas morfologías y estéticas determinadas (Fig. 7), en un amplio marco territorial, indican la evidencia de intercambios, contactos o influencias que se establecen con una gran rapidez, probablemente fruto de la solidez de las redes de información entre los grupos de la primera mitad del III milenio cal. AC.

El análisis de las materias primas implicadas en la fabricación de los recipientes cerámicos (Clop y Álvarez, en Alcalde et alii, 1997) permite establecer tres grupos petrográficos diferenciados, si bien todos entran en la categoría de producciones locales. Destaca, pues, el uso exclusivo de materias primas procedentes de depósitos del entorno inmediato al yacimiento. La presencia, en algunos de los fragmentos analizados, de elementos minerales de origen volcánico ha permitido fijar para estos casos una distancia aproximada de $4 \mathrm{Km}$ desde el yacimiento.

Se trata, en general, de producciones relativamente poco especializadas. Otro dato significativo es la homogeneidad constatada en la materia prima utilizada para la manufactura de los recipientes cerámicos, independientemente de su forma y adscripción estilística, documentándose también unas características análogas para la fabricación de las vasijas-horno, recipientes utilizados en actividades tecnológicas específicas.

El resto de materias utilizadas en la producción de objetos líticos, instrumentos vinculados al procesado de vegetales (molinos, morteros), instrumentos vinculados a la actividad metalúrgica (toberas), a la actividad textil (fusayola) y a las actividades agrícolas (hachas y hoces), son también en su practica mayoría de origen local. Cabe mencionar en este sentido la utilización de sílex, cuarzo, basalto y arenisca, todas ellas materias disponibles en el entorno inmediato del asentamiento. 


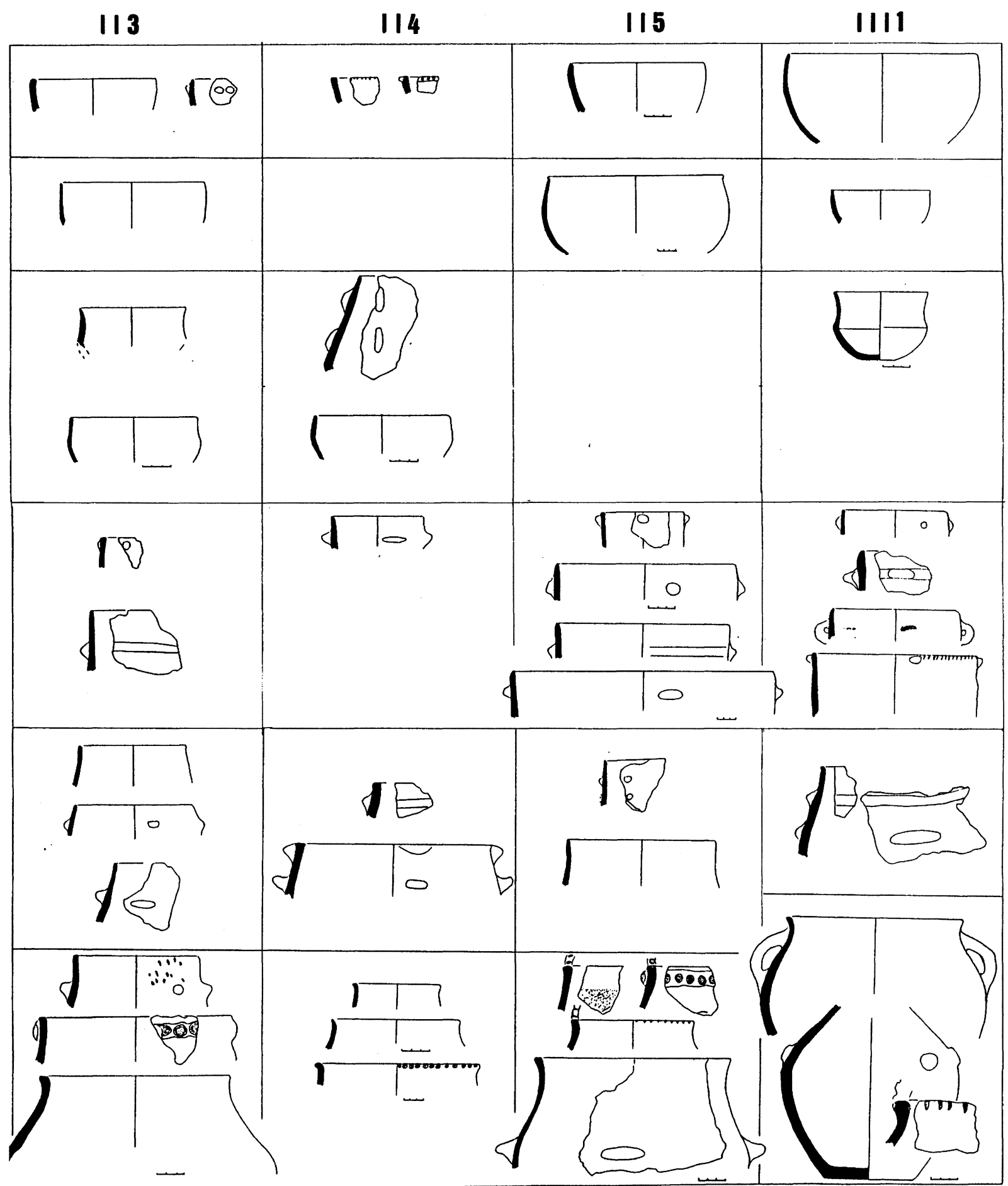

Fig. 7. Formas cerámicas sin decoración campaniforme. 


\section{EL CASO PARTICULAR DE LAS ACTIVIDADES METALÚRGICAS}

El registro arqueológico ha proporcionado un conjunto importante y diversificado de elementos relacionados con la actividad metalúrgica. Mayoritariamente se trata de vasijas-horno, utilizadas en el proceso de reducción de minerales de cobre. Estos fragmentos cerámicos presentan la superficie exterior agrietada, con adherencias escoriáceas y restos de mineral de cobre en su cara interna, con claros indicios de rubefacción y de haber estado sometidos a altas temperaturas.

En la Bauma, las vasijas-horno consisten en recipientes de diferentes formas y tamaños, pero dado su estado fragmentario solo en un caso ha sido posible reconstruir el tamaño $(23 \mathrm{~cm}$ de diámetro de boca), y en otros tres casos podría tratarse de vasos abiertos de paredes rectas y posible perfil troncocónico (Fig. 8). Los fragmentos con decoración campaniforme de estilo pirenaico, corresponderían también a formas simples de tipo abierto, principalmente cuencos. Se han identificado un total de 65 fragmentos cerámicos (2), aunque existen algunos más que pudieron haber tenido esta misma función. Su distribución en cada uno de los cuatro niveles no es uniforme, aunque en todos ellos hay fragmentos decorados.
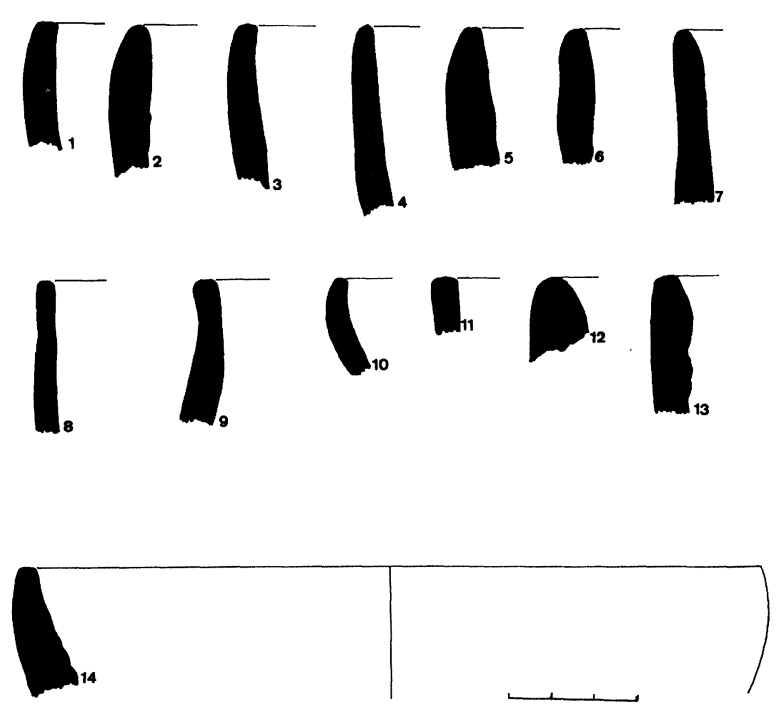

Fig. 8. Fragmentos de borde de vasijas-horno del yacimiento.

(2) Hasta la fecha es el conjunto publicado más numeroso de vasijas-horno, le sigue El Ventorro (Madrid) con 63 fragmentos. (Priego y Quero, 1992).
En los lisos se observa una mayor presencia en el nivel II.5, seguido del III.1 (Tab. 5).

\begin{tabular}{|c|c|c|}
\hline Nivel & Sin Dec. & Decorados \\
\hline III.1 & 14 & 6 \\
\hline II.5 & 30 & 7 \\
\hline II.4 & 3 & 2 \\
\hline II.3 & 0 & 3 \\
\hline
\end{tabular}

Tab. 5. Distribución de vasijas-hornos por niveles arqueológicos.

La estimación del numero mínimo de vasijas es muy compleja, dado su alto grado de fragmentación. Sin embargo, teniendo en cuenta el número de bordes diferenciados y la decoración, tendríamos un mínimo de 14 vasos para el conjunto de fragmentos lisos y 5 para los cuencos de tipo campaniforme.

En una publicación preliminar clasificamos estos elementos como fragmentos de crisoles (Alcalde et alii, 1994), clasificación que en la publicación definitiva (Alcalde et alii, 1997) ha sido revisada, otorgándole la función de vasijas-hornos. Únicamente el fragmento $\mathrm{n}^{\circ} 12$ de la figura 8 podría pertenecer en realidad a un crisol, pero no es posible asegurarlo por su pequeño tamaño y desarrollo.

Además de las vasijas-horno, se han recuperado dos toberas de arcilla, una en el nivel II.3 y otra en el nivel II.5 (Fig. 9). La primera es de forma cilíndrica y con una perforación longitudinal; conserva completa la parte inferior con una anchura de $2.2 \mathrm{~cm}$, ensanchándose hasta $2,7 \mathrm{~cm}$ en el extremo fracturado. La perforación mide $8 \mathrm{~mm}$ de diámetro. La segunda tobera se encuentra fragmentada en los dos extremos. El diámetro del cuerpo es $2,3 \mathrm{~cm}$ mientras que en el extremo fragmentado de la boquilla aumenta a $2,6 \mathrm{~cm}$ y la anchura de la perforación longitudinal es de $7 \mathrm{~mm}$. La fractura en la zona de la cabeza nos impide sa-

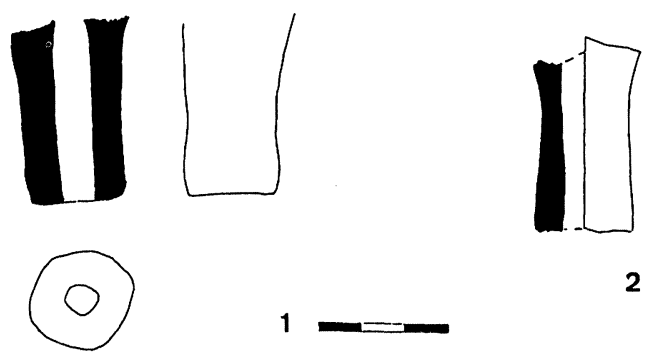

Fig. 9. Toberas de la Bauma del Serrat del Pont. 
ber si corresponde al tipo de tobera de trompa, similar a la de la cueva de Peyroche II (Ardeche, Francia), o su desarrollo sería de borde engrosado como las de Cabane des Clausis (Altos Alpes, Francia) (Gattiglia y Rossi, 1995) o la procedente de Buraco da Pala (Tras os Montes, Portugal) (Sanches, 1996).

Completan el inventario de materiales dos pequeños restos de fundición, de los niveles II.3 y II.5, y quizás un canto rodado de forma oval con una concavidad en una de sus caras, es decir, una piedra con cazoleta, que se podría relacionar con la trituración del mineral.

En relación a manufacturas metálicas, se ha recuperado una punta de flecha en el nivel III.1, un punzón biapuntado en el nivel II.4, un fragmento de aguja o punzón y un fragmento de varilla procedentes del nivel II.3 (Fig. 10). Esta última presenta una sección ovalada y la parte distal está marcada por un ligero rebaje que debería facilitar su atadura. La flecha presenta una punta triangular plana simple sin alerones ni arista bifacial y con pedúnculo ancho. Los paralelos de este tipo de objeto son numerosos, destacando la procedente del yacimiento de la Pedra del Sacrifici (Osona), a pesar de que algunos investigadores han discutido su posición estratigráfica (Muñoz, 1965).

El punzón biapuntado tiene una longitud aproximada de $50 \mathrm{~mm}$., una anchura máxima de 4 $\mathrm{mm}$., con uno de los extremos ligeramente torcido. Se trata de un instrumento relativamente bien documentado en contextos del calcolítico-bronce antiguo de Cataluña como, por ejemplo, en la Cova d'Aigues Vives (Olius, Lleida) (Serra Vilaró,1923) o en la cova de l'Heura (Ulldemolins, Tarragona) (Vilaseca, 1973).

Una parte de estos materiales han sido analizados para estudiar su composición. La técnica empleada ha sido la fluorescencia de rayos $X$ en energía dispersiva (XRF-EDS) (3) y los valores expresados en $\%$ en peso quedan recogidos en la tabla 6.

Los resultados obtenidos en los análisis de los restos de vasijas horno nos muestran un uso de materias primas diferentes, incluso dentro de un mismo nivel de ocupación. Estos restos corresponden a un proceso de reducción de minerales de cobre, principalmente de carácter no ferruginoso,

(3) Los análisis se realizaron dentro del Proyecto Arqueometalurgia de la Península Ibérica (PB92-0315) en el hoy Instituto de Patrimonio Histórico Español (IPHE) del Ministerio de Educación y Cultura.
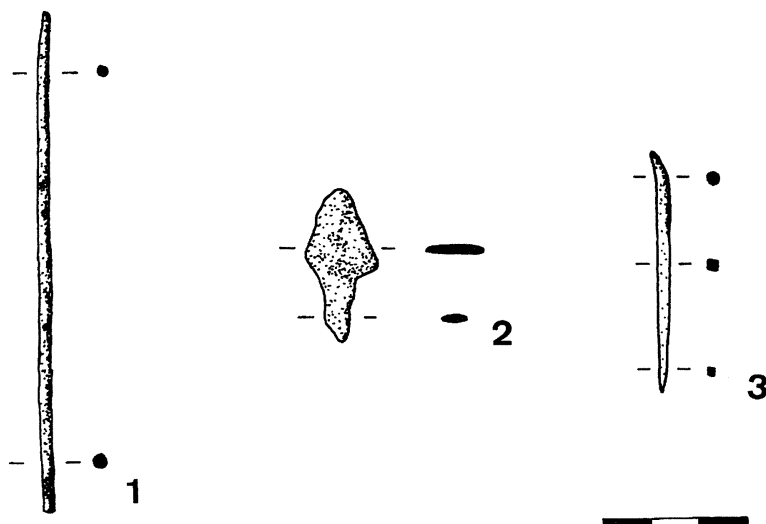

Fig. 10. Objetos de metal recuperados en los niveles del III milenio cal. AC.

dada la escasa cantidad de hierro presente en su composición, y sin adición de fundentes.

La variaciones detectadas en los elementos analiżados señalan la utilización de minerales de cobre con alta proporción de antimonio en las muestras PA6324 (6.89\%) y PA6328 (mayoritario aunque no cuantificado), ambos del nivel II.5, mientras que en el resto de adherencias debió usarse otro u otros tipos de minerales, ya que el antimonio apenas se presenta como impureza. Entre esos otros restos se puede diferenciar un mineral caracterizado por un polimetalismo cobre-estaño en el fragmento PA6326 (nivel II.4), y otro mineral de relativa pureza en los fragmentos PA6327 y PA6325 (nivel II. 5).

Una cuarta variedad de mineral se identifica en el resto de fundición del nivel II.3 (PA6353) en el que aparece cuantificada una relativa cantidad de plomo. La reducción de minerales de cobre con plomo queda confirmado en ese mismo nivel por la presencia de este elemento en el análisis del punzón o aguja (PA6332). Esta asociación cobreplomo u otra similar fue también utilizada durante la ocupación calcolítica, ya que, aunque en ninguna de las adherencias cerámicas se ha identificado, aparece en un resto de fundición (PA6352) y en la punta de flecha (PA6335). En esta última pieza la presencia de antimonio lo diferencia de los anteriores minerales y pudiera tratarse de otro recurso mineral o de una pieza de otra procedencia.

Destaca en este conjunto de análisis la gran diversidad en el polimetalismo de los minerales, hecho que nos ha conducido a investigar y a realizar un muestreo de las diferentes formaciones mineralógicas existentes en el valle. 


\begin{tabular}{|l|l|c|c|c|c|c|c|c|c|c|}
\hline Análisis & Objeto & $F e$ & $N i$ & $C u$ & $A s$ & $A g$ & $S n$ & $S b$ & $P b$ & $N i v e l$ \\
\hline PA6353 & Resto fundición & 0.344 & 0.190 & 53.89 & 2.240 & 0.280 & 41.37 & 0.090 & 1.599 & II.3 \\
\hline PA6332 & Aguja o punzón & 0.366 & 0.192 & 75.32 & nd & 0.025 & 23.51 & 0.031 & 0.629 & II.3 \\
\hline PA6329 & Punzón biapuntado & 0.334 & nd & 99.52 & nd & 0.076 & nd & 0.067 & nd & II.3/II.4 \\
\hline PA6326 & Adh. cerámica & nd & nd & 94.65 & nd & 0.053 & 4.642 & 0.652 & nd & II.4 \\
\hline PA6327 & Adh. cerámica & nd & tr & 99.20 & nd & 0.055 & 0.547 & 0.054 & tr & II.5 \\
\hline PA6328 & Adh. cerámica & & & det & & & & det & & II.5 \\
\hline PA6324 & Adh. cerámica dec. & nd & nd & 91.70 & 0.746 & 0.059 & 0.606 & 6.890 & nd & II.5 \\
\hline PA6325 & Adh. cerámica dec. & nd & nd & 99.72 & nd & 0.062 & nd & 0.212 & nd & II.5 \\
\hline PA6352 & Resto fundición & 0.190 & nd & 91.51 & nd & nd & 7.687 & 0.038 & 0.561 & II.5 \\
\hline PA6335 & Punta flecha & 0.057 & nd & 91.30 & nd & 0.053 & 7.096 & 0.494 & 0.172 & III.1 \\
\hline
\end{tabular}

Tab. 6. Composición de los materiales de la Bauma del Serrat del Pont (La Garrotxa, Girona). Valores expresados en \% en peso $(\mathrm{det}=$ presente; $\mathrm{nd}=$ no detectado; $\mathrm{tr}=$ trazas $)$.

\section{EL ÁREA DE CAPTACIÓN DE MATERIAS PRIMAS METALÚRGICAS}

La alta Garrotxa, que forma parte del pre-Pirineo, es una zona montañosa y abrupta debido a la fuerte actividad tectónica que actuó durante la orogenia alpina. Las rocas que la constituyen, cálcareas y margas sobre todo, se sedimentaron durante el eoceno, hace unos 40 millones de años, posteriormente se plegaron y fracturaron, originando un conjunto de fallas y cabalgamientos que modelaron la zona. Algunos de estos cabalgamientos facilitaron el afloramiento de rocas metamórficas y granitos del paleozoico, destacándose el hecho que tanto los granitos, como en menor medida las rocas metamórficas, afloraron junto con mineralizaciones de diversos tipos. Las cuñas de granitos y rocas paleozoicas alargadas, en dirección E-W, se hallan sobre todo en la parte alta de la zona y afloran de manera intermitente. Así, se localizan debajo del Puig de Bassegoda (Ayora y Casas, 1985), antes de Sant Aniol de Agujes, en el valle de Ormoier, en la riera de Oix debajo del Montpetit, por encima de Rocabruna y cerca del pueblo de La Manera. En todas ellas hay localizadas mineralizaciones y posibles minas. De este a oeste se hallarían debajo del Bassegoda al lado de la casa de Can Manera, en el valle de Riu al lado de la casa de "can Agustí de Riu", en el valle de Ormoier en la zona de los Casals, al oeste del pueblo de Oix en la Ferreria y Can.Quic y finalmente en las Ferreres al norte de Rocabruna.

Las mineralizaciones más abundantes se encuentran en los granitos, presentándose en forma de filones, los cuales tienen un origen posterior a los granitos. Los filones están compuestos de sulfatos de baritina, galena, pequeñas cantidades de calcopirita y alteraciones posteriores en forma de malaquita, gohetita y azurita. También se halla una mineralización estratiforme en los minerales paleozoicos que afloran al norte de la Ermita de Riu. La mineralización está formada por galena, esfalerita, pirita y no presenta alteraciones en forma de carbonato básico de cobre (malaquita).

Se dispone de referencias históricas que evidencian la extracción de minerales de cobre en la cabecera y valles próximos a la Bauma del Serrat del Pont:

"en el valle de Riu, en la vertiente Oeste del pico de Bassegoda, exploró la mina San José, en el sitio llamado Basch d'Agustí, un filón irregular de galena acerada con ganga de cuarzo, que lleva pintas de chalkosina, con $0,30 \mathrm{~m}$ de espesor que arma en la pizarra siluriana." (Vidal, 1886: 369).

Se cita también que en Riu:

“... en la orilla derecha del río se concedió la mina Providencia sobre un filón de baritina y siderosa con bolsadas pequeñas de cobre gris y chalkosina, que arma en granatina, cuya roca, por su gran dureza ha impedido la exploración del criadero. En la misma orilla, aguas arriba, asoma una roca feldespàtica con manchas de malaquita azul y verde, presentando un filón dirigido al E $10^{\circ} \mathrm{N}$ con un grueso de $40 \mathrm{~cm}$ ". (Vidal, 1886: 339).

Pueden citarse también las referencias sobre las explotaciones de Rocabruna, en uno de los valles de los afluentes del río Llierca:

"unos trabajos antiguos, cuyo origen se ignora en la localidad, descubren, en el sitio llamado Las ferreres, distante tres kilometros del pueblo, casi en la divisoria de fronteras, un filón vertical de cuarzo con baritina, encerrando ri- 
ñones de burnonita, chalkosina y malaquita" (Vidal, 1886: 342).

En los trabajos de Solà-Morales encontramos más precisiones sobre estas minas de Rocabruna, en las que en 1735 se otorgó una licencia para:

"iniciar alguna cata entre los términos de esta última parroquia (Molló) y la de Rocabruna, y particularmente en la sierra de Vernadell, obteniendo cobre en buena proporción (de 16 onzas de tierras, 2 1/2 de cobre)" (Solà Morales, 1956: 1.622-1.623).

Se tiene constancia de la explotación en época romana en la mina de La Ferrera de Rocabruna. De esa época se conserva aún el interesante entramado de galerías, pequeñas y estrechas, las cuales presentan alteraciones en forma de carbonatos de cobre. Estas minas fueron las últimas en donde se extrajo el mineral, cerrándose hace tan solo unos 30 años. Se dispone de algunos datos sobre su producción, así entre el 15 de enero y el 8 de marzo de 1742 se obtuvieron:

“ $1.248 \mathrm{~kg}$ aprox. de cobre fino, $75,5 \mathrm{~kg}$ aprox. de cobre roseta, $78 \mathrm{~kg}$ aprox. de matas de cobre finas, $145,5 \mathrm{~kg}$. aprox. de menas de cobre, $707,2 \mathrm{~kg}$ aprox. de mena de plata triada" (SolàMorales, 1956: 1.628).

A partir de 1738 D. Martín Verdun y Compañía explotan una mina en la sierra del Vernardell y Solà-Morales (1956: 1.627) menciona una carta de 1739 en la que se especifica que:

"de la mina delVernardell se sacaban de 3 libras y 5 onzas de plomo (o sea, de galena argentífera) 2 onzas de plata, sin contar con una mayor abundancia de cobre que se extraía también y por el cual parece se hallaba particularmente interesado el Intendente Gl. de Cataluña, Sartine, para la fabricación de cañones".

Estos documentos nos han orientado en la prospección geológica de la zona con el objetivo de localizar los afloramientos de minerales y extraer muestras. Los mapas geológicos (4) e informes nos permiten completar este panorama sobre materias primas (Fig. 11).

(4) Corresponden a esta zona las hojas 256 (Ripoll) y 257 (Olot) del Mapa Geológico de España, escala 1:50.000 del Instituto Tecnològico GeoMinero.

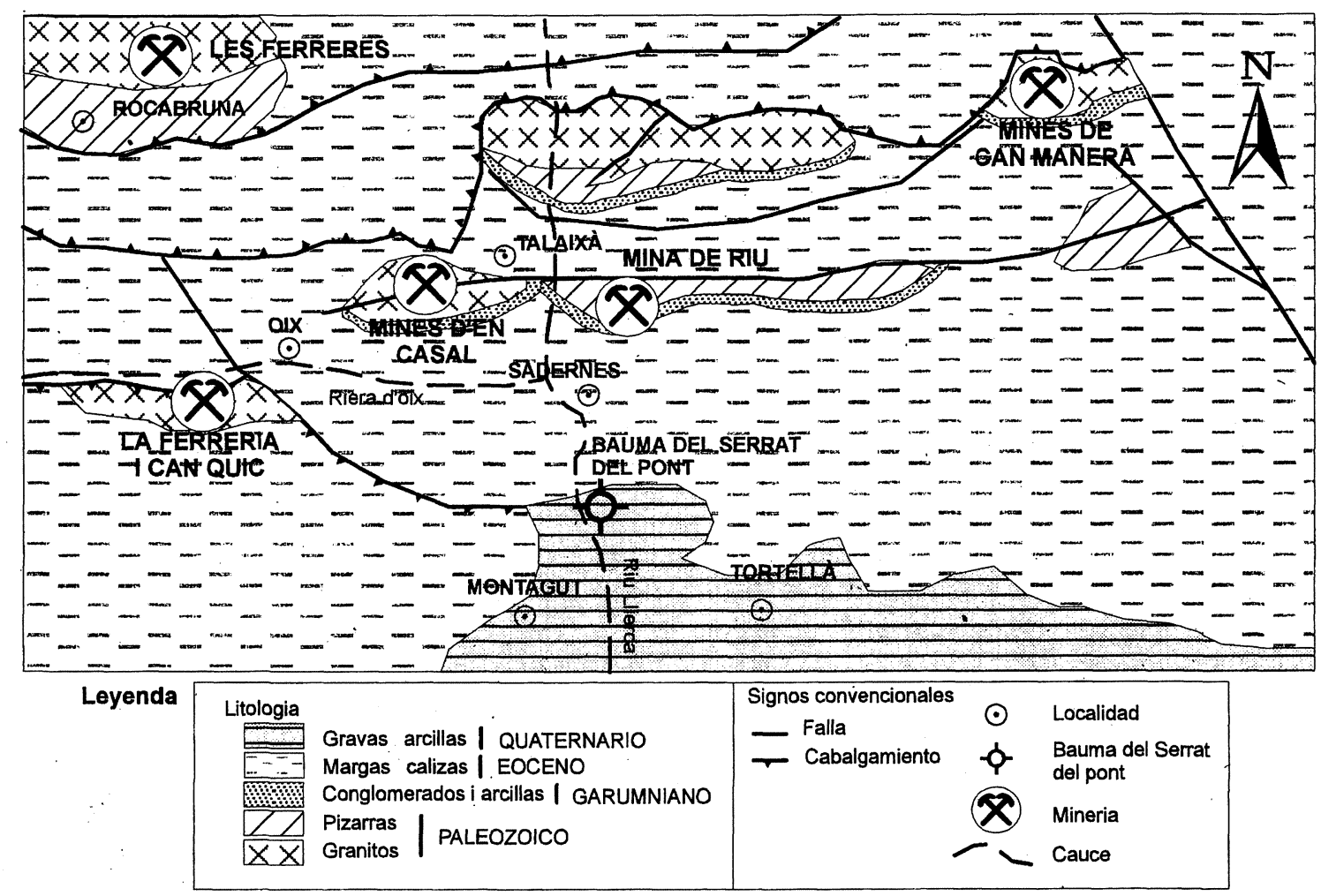

Fig. 11. Mapa geológico de la zona con la ubicación de los diferentes yacimientos mineralógicos muestreados.

T. P., 55, n. $^{\circ} 1,1998$ 
Contamos en estos momentos con 8 muestras analizadas de dos estaciones. La Ferrera en Rocabruna y Manera. Se han realizado análisis (5) de Difracción de Rayos X para identificar las fases cristalinas en cada una de ellas (Tab. 7). Los resultados confirman el polimetalismo ya comentado y la existencia de arseniatos de cobre en las muestras de color verdoso de La Ferrera, pequeños indicios de estaño en las de color violeta y presencia de antimonio en ambos tipos de muestra, además de indicios de bismuto y algo de plomo. Por su parte, en las muestras de la Manera se ha identificado principalmente compuestos de cobre, estaño y hierro y más esporádicamente arsénico y níquel.

\begin{tabular}{|c|l|l|}
\hline Mina & \multicolumn{1}{|c|}{ Especie } & Color muestra \\
\hline \multirow{5}{*}{ LA FERRERA } & Tenorita - CuO & Verdoso-violeta \\
& Paramelaconita - Cu403 & Violeta \\
& Spertinita - Cu (Oh)2 & Verdoso \\
& Hidroromarchita - Sn3O2 (OH) 2 & Violeta \\
& Valentinita - Sb203 & Violeta \\
& Senarmontita - Sb203 & Verdoso \\
& Clinoclasa - Cu3(AsO4)(OH)3 & Verdoso \\
& Lammerita - Cu3(AsO4)2 & Verdoso \\
& Discrasita - Ag3Sb & Violeta \\
& Magnetita - FeFe204 & Verdoso \\
MANERA & Eschafarzikita - FeSb206 & Verdoso \\
& Hematites - Fe2O3 & Verdoso y Marrón \\
& Anargita - Cu3AsS4 & Verdoso \\
& Casiterita - SnO2 & Marrón \\
& Bronce - Cu6Sn\% & Verdoso \\
& Cuprita - Cu2O & Marrón \\
\hline
\end{tabular}

Tab. 7. Especies minerales identificadas por Difracción de Rayos X.

Por tanto, y a falta de un estudio más detallado y completo de las mineralizaciones del entorno de la Bauma del Serrat del Pont, se puede decir que existe concordancia entre los minerales aprovechados en el yacimiento y los de las minas próximas. Determinar a cuál de ellas en concreto podrían corresponder todavía se nos escapa, pero posiblemente, dada la gran variedad de minerales transformados, no fue una sola, sino varias de estas minas o mineralizaciones las que fueron beneficiadas en tiempos prehistóricos.

(5) Estos análisis se han realizado en la C.A.I. de Difracción de Rayos X de la Facultad de Ciencias Químicas de la Universidad Complutense de Madrid. Se ha empleado un difractómetro Philiphs X'Pert en plataforma multipropósito. Agradecemos a Julián Velázquez la atención que nos ha prestado y su colaboración en la interpretación de los resultados.

\section{EL TRABAJO METALÚRGICO: VASIJAS- HORNO Y ALEACIONES}

La reutilización de vasijas de carácter doméstico para tareas metalúrgicas es un hecho ampliamente constatado en la Prehistoria de la Península Ibérica (Gómez Ramos, 1996b), sin embargo aún cuesta comprender el por qué de la falta de especificidad en su manufactura, como elemento que participa en una actividad supuestamente especializada. La constatación continua del uso de diferentes formas en un mismo yacimiento, tal y como hemos visto para la Bauma, formas a su vez diferentes entre yacimientos, enfatiza aún más ese carácter inespecífico del contenedor utilizado en la transformación del mineral. Los análisis de pastas de estos fragmentos hasta ahora siempre revelan que no se diferencian en nada del resto de las producciones cerámicas de los yacimientos en los que aparecen, realizadas generalmente con arcillas de origen local (Montero, 1994: 227; Rovira y Montero, 1994: 160), hecho que también corrobora el único fragmento analizado de la Bauma.

El que además de las vasijas empleadas en las labores más cotidianas se llegue a emplear otras decoradas, en este caso con estilo campaniforme, cuyo valor simbólico no añade nada a su función, ya que el destino final es la rotura completa de la vasija, nos sugiere la idea de un reaprovechamiento de piezas fuera de uso.

Las vasijas-horno con decoración campaniforme de la Bauma incrementan la lista de fragmentos y yacimientos con pautas metalúrgicas similares, aunque en este caso su número, 18 , es superior al total de fragmentos identificados en otros lugares: las dos piezas de ElVentorro en Madrid (Quero y Priego, 1992), los dos fragmentos de un mismo vaso de Sont Matge en Mallorca (Waldren, 1986: 6) y un fragmento de El Acebuchal en Sevilla (Harrison et alii, 1976: 90) (Fig. 12).

\subsection{La cuestión de los bronces}

Otro aspecto de gran interés conocido gracias a los análisis de los materiales metálicos de La Bauma es la presencia de aleaciones con estaño. Los dos elementos pertenecientes al nivel II.3, correspondiente al Bronce Antiguo y con una fecha de referencia de $3840 \pm 90 \mathrm{BP}(2560-1975 \mathrm{cal}$. AC), son bronces. El resto de fundición parece corres- 

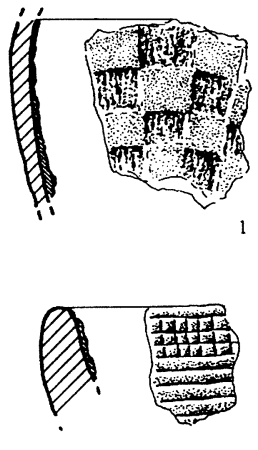

3
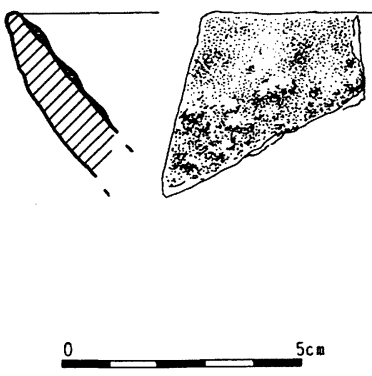
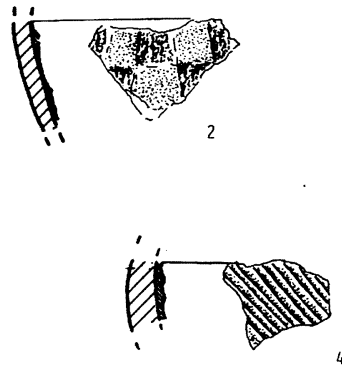

Fig. 12. Vasijas horno con decoración campaniforme: 1-2 Sont Matge; 3-4 Bauma del serrat del Pont; 5-6 El Ventorro.

ponder a un fragmento de metal formado en la transformación conjunta de mineral de cobre con mineral de estaño. La mezcla de ambos minerales impide controlar la proporción final de la aleación, produciendo generalmente contenidos altos de estaño si la temperatura de trabajo es elevada (6), lo que a su vez genera un metal con más impurezas de hierro. Esta situación concuerda con la composición de la aguja o punzón (PA6332), con una tasa alta de estaño $(23.5 \% \mathrm{Sn})$ que no permite dudar de su adición intencional al metal.

$\mathrm{Se}$ necesitan condiciones reductoras muy estrictas si se quiere que el óxido de estaño (casiterita) entregue el estaño metálico durante el proceso de reducción conjunta. El ambiente en el "horno" ha de ser por tanto muy rico en monóxido de carbono, lo cual implica poca ventilación y una buena alimentación de carbón para mantener la

(6) El procesamiento conjunto de mineral de estaño y de cobre es práctica común a lo largo de toda la Prehistoria Reciente. Está documentado en los niveles de transición del Bronce Antiguo al Medio de Monte Aguilar I (Navarra), en el yacimiento del Bronce Final de Peña Negra (Alicante) (Gómez Ramos, 1996b: 136 y 138) o en el Castrelín de San Juan de Paluezas (León) durante la segunda Edad del Hierro (Fernández-Posse et alii, 1993: 208).

T. P., 55, n. ${ }^{\circ} 1,1998$ temperatura entre $900^{\circ}$ y $1200^{\circ} \mathrm{C}$, a partir de esta última la eficacia de la reacción aumenta y ya es bastante fácil obtener bronce (Rostoker et alii, 1983: 25-26).

En los materiales calcolíticos de la Bauma es más difícil asegurar la intencionalidad de la aleación. Solo tres de ellos presentan porcentajes de estaño por encima del $1 \%$. En la adherencia cerámica (PA6326) del nivel II.4 parece que se redujo un mineral de cobre con asociación natural de estaño, del tipo documentado en las minas de $\mathrm{La} \mathrm{Fe}$ rrera, o en la más alejada de Riner, también en el área pirenaica (Serra Vilaro, 1924). En este caso, el estaño atrapado en la pared escoriácea ha sido escaso, y desconocemos qué proporción pudo pasar al metal. Esta cantidad, sin embargo, no debió ser elevada, ya que en las escorias y adherencias suelen cuantificarse valores porcentuales mucho más altos, a excepción del cobre como metal de base, que los que se detectarían en el metal obtenido durante el proceso en que se formaron.

El resto de fundición PA6352, perteneciente al nivel II.5, con un porcentaje del $7.68 \% \mathrm{Sn}$, se sitúa por encima, pero próximo a la encrucijada del $6 \%$, considerado de manera teórica límite para la formación de un bronce natural. En esa misma situación $(7.09 \% \mathrm{Sn})$ se encuentra la punta de flecha del nivel III.1 (PA6335).

Los argumentos contrarios a una aleación deliberada en estas dos piezas se centran en la propia tecnología de fundición. En hornos como los descritos para esta época (vasijas-horno), que no permiten el mantenimiento de altas temperaturas y trabajan en procesos reductores, resulta fácil retener el arsénico del mineral original, variando la proporción en función de la temperatura, pero es muy difícil que el metal (cobre) retenga estaño. Este queda en su mayor parte en las adherencias y restos escoriáceos en forma de óxido. Por tanto, aunque se utilicen minerales de cobre ricos en estaño no se obtendrán bronces naturales mientras no se domine una mayor temperatura en el horno. Esta situación es la que se constata en el yacimiento madrileño de Villaviciosa de Odón, donde el procesamiento de mineral de cobre con estaño no produjo bronce (Rovira y Montero, 1994: 166-67).

Sin embargo, en la Bauma están documentadas toberas para ventilación, elementos que ayudan a aumentar la temperatura de trabajo y proporcionan mejores condiciones de procesado. Una de ellas apareció en el nivel del Bronce Antiguo, en el que hemos deducido temperaturas altas durante la 
transformación conjunta de minerales de cobre y estaño. La otra tobera pertenece al mismo nivel II.5 que el resto de fundición de bronce. Por tanto, los metalúrgicos de la Bauma pudieron estar trabajando en condiciones más propicias que otros de sus contemporáneos peninsulares, logrando bronces de manera accidental. En este sentido, resulta llamativa la presencia de toberas de arcilla únicamente en el tercio norte peninsular (7). $\mathrm{Ni}$ siquiera durante el Bronce Medio han sido documentadas en las zonas centrales y meridionales de España, cuando son de uso común desde el Calcolítico en Francia, Italia o países de Europa central (Gattiglia y Rossi, 1995).

En cualquier caso, sea natural o intencionada la presencia de estaño en el metal de los niveles calcolíticos, el material de la Edad del Bronce (nivel II.3) corrobora y consolida una cronología para làs aleaciones de bronce más antigua en el norte de la Península Ibérica que en el sur, tal y como expusieran Fernández-Miranda y otros (1995).

Las fechas actualmente conocidas no establecen ningún desfase entre el norte de la Península Ibérica y el resto de Europa. En el entorno más cercano a la Bauma, conocemos el puñal de remaches delAbri du Capitaine (BassesAlpes, Francia) asociado a cerámica campaniforme, en niveles no del todo claros, y por tanto sin una vinculación directa a la fecha de $4100 \pm 140 \mathrm{BP}(3000-2200 \mathrm{cal}$. AC) (Guilaine, 1984: 179-80; Fernández-Miranda et alii, 1995: 61-62), por otra parte demasiado imprecisa por su alta desviación estandar. Su bajo contenido en estaño $(\sim 3-5 \%)$ nos coloca en la misma posición de duda sobre su intencionalidad que los materiales calcolíticos de la Bauma. No obstante, empiezan a identificarse bronces claramente aleados en contextos contemporáneos, como los dos punzones de Guidoiro Areoso (Pontevedra) con porcentajes elevados de estaño (21.52\% y $21.86 \%$ ) (Comendador, 1995), que se relacionan con la fecha de $4020 \pm 40 \mathrm{BP}$ (2830$2410 \mathrm{cal}$. AC), y un hacha plana de Newgrange (Irlanda) con un $13 \%$ Sn, fechada también por radiocarbono (8) entre 2800-2600 BC (Denison, 1994).

(7) Las dos toberas de la Bauma se unen al escaso repertorio conocido, compuesto hasta la fecha únicamente por yacimientos portugueses como Buraco da Pala (Sanches, 1996), Pedra do Ouro y Vila Nova de Sao Pedro, estas dos últimas reccopiladas por Gómez Ramos (1996a) en un trabajo donde plantea esta situación.

(8) Los autores no incluyen la referencia completa de la datación, y el arco cronológico que ofrecen da la sensación de corresponder a una sola desviación standar.
En consecuencia, podríamos situar el conocimiento de la aleación con estaño en un momento anterior a mediados del III milenio cal. AC, cronología en la que los materiales calcolíticos de la Bauma no resultarían anómalos (la fecha más antigua sería $4200 \pm 70 \mathrm{BP} ; 2920-2490$ cal. AC, asociada al resto de fundición de bronce).

Este conocimiento de la aleación no impidió que durante mucho tiempo siguieran fabricándose de manera mayoritaria objetos de cobre. En la propia Bauma se aprecia esta circunstancia en la composición de algunas vasijas-horno y en el punzón de cobre del nivel II.4. De hecho, en Cataluña la mayoría de los objetos del Bronce Antiguo analizados en el Proyecto Arqueometalurgia de la Península Ibérica son cobres o cobres arsenicados (Rovira et alii, 1997).

\section{LA PRODUCCIÓN DE METAL EN EL ASENTAMIENTO DE LA BAUMA DEL SERRAT PONT: IMPLICACIONES SOCIO-ECONÓMICAS}

Tal como se evidencia a partir de los datos expuestos en este trabajo, los grupos humanos que habitaron este abrigo durante el intervalo temporal analizado hacían un uso diversificado de la amplia variedad de recursos naturales disponibles en el valle del Llierca. Esta diversificación incluye desde los recursos animales y vegetales, adquiridos a partir de una practica puntual de las actividades de caza, pesca y recolección, hasta los recursos minerales implicados en la producción de recipientes cerámicos y objetos de metal.

El aprovechamiento temporal y no intensivo de esta gran variedad de recursos, junto con las características particulares que presenta el lugar de habitación, nos inclinan a pensar que, si bien la producción metalúrgica desempeñaba un papel importante dentro del conjunto de procesos de trabajo realizados durante estas ocupaciones, no constituye, sin embargo, una actividad exclusiva. Esta última consideración vendría reforzada por el hecho de que el mineral utilizado como materia prima para la fabricación de instrumentos de metal es relativamente variable, no haciéndose uso exclusivo de una misma mineralización, característica que permite proponer un cierto grado de provisionalidad. De esta manera, las actividades implicadas en el proceso de producción metalúrgica quedarían plenamente integradas dentro de la 
estrategia económica general practicada, siendo uno más de los procesos de trabajo destinados a la subsistencia y mantenimiento de las diversas comunidades que ocuparon este abrigo. De todos modos, debemos citar como probable excepción a esta dinámica general la ocupación del nivel II.5.

Cabe preguntarnos, pues, dadas las características concretas que presentan las ocupaciones, el motivo de estos desplazamientos puntuales al valle del Llierca. Partiendo de la base de que el registro arqueológico nos muestra la instalación de un grupo reducido de personas, el procesamiento y consumo de un amplio espectro de productos animales y vegetales y la fabricación local de la mayor parte de los instrumentos de trabajo requeridos para satisfacer las necesidades básicas, es factible considerar que la unidad social implicada en cada ocupación formara parte de una comunidad o poblado de carácter estable, localizado en terrenos más aptos para el desarrollo de las actividades agrícola-ganaderas.

A pesar de las prospecciones realizadas en el entorno inmediato del abrigo, no se ha localizado ningún vestigio de hábitat permanente, ni en la zona del Valle del Fluvià, ni en sus proximidades, que por sus características orográficas sería lugar idóneo para este tipo de asentamiento, tal y como muestra su ocupación en periodos anteriores, con un modelo de complementariedad entre asentamientos de valle y los ubicados en zonas más agrestes (Bosch, 1994). La actual ausencia de asentamientos del III milenio cal. AC en los valles de la zona de la Garrotxa no es sinómino, a nuestro entender, de su inexistencia, pues como ha evidenciado últimamente la investigación, los hábitats del llano tienen una localización difícil y azarosa, debido tanto a los fenómenos postdeposicionales (fuerte actividad agrícola,...) como por los vestigios que los configuran (estructuras negativas: fosas, silos,...). En efecto, algunos asentamientos excavados recientemente, como el Institut de Batxillerat en Osona (Boquer et alii, 1995), el de Minferri en el Segrià (Llusa et alii, 1990; Equip Minferri, 1997) o también en el Vallès, de grandes dimensiones que pueden alcanzar varias hectáreas de extensión, y con indicadores de una fuerte actividad agrícola-ganadera predisponen a revisar los modelos de distribución del poblamiento vigentes para este periodo desde los años 60 . Ese modelo insistía en la dualidad de pobla- ciones o "grupos culturales" a partir de la distribución geográfica de los asentamientos (por ejemplo, Tarradell, 1962). En la interpretación actual, esta separación se transformaría en una complementariedad económica y social, dada la situación de estos asentamientos en valles interiores rodeados de pequeñas cordilleras donde se ubican un número importante de asentamientos coetáneos, como los sepulcros megalíticos; las cuevas sepulcrales o de hábitat, debían tener un papel complementario (actividades de pastoreo, territorios de explotación, ...) (Boquer et alii, 1995). La Bauma del Serrat del Pont, permite avanzar en la definición de este modelo, a partir esta vez de la documentación de uno de estos asentamientos pequeños que debían completar el modelo de distribución poblacional en este III milenio AC.

En este marco, la práctica de la actividad metalúrgica podría ser una de las causas que motivaran estos desplazamientos, si bien hay que remarcar de nuevo el carácter no específico de la misma. Esta se realizaría durante un intervalo temporal concreto del año y todos los procesos de trabajo relacionados con la misma, desde la captación de los minerales hasta la producción de objetos de cobre, se desarrollarían en el valle del Llierca. De aquí la denominación de taller. Cabe pensar en que esta instalación de la Bauma no es la única y que este tipo de asentamientos-taller, cerca de las zonas de afloramiento de mineral, serían más generalizadas. Hasta el momento, y en un marco temporal más amplio y para la zona del nordeste peninsular, únicamente se han relacionado con la actividad metalúrgica dos áreas principales: la zona de Riner en el Solsones (Lleida) (Serra Vilaró, 1924) y la zona de las montañas de Prades (Tarragona) (Vilaseca, 1973). En ambos casos se trata de antiguos hallazgos, con un nivel de información muy parcial. Hay que añadir a esta relación los resultados más recientes obtenidos para el yacimiento de Cova del Frare (Martín, 1992), con la presencia también de vasijas-horno.

La documentación detallada del taller de la Bauma del Serrat del Pont se convierte, pues, en documento clave para el conocimiento del marco socioeconómico en el que se llevaron a cabo las primeras producciones de cobre y bronce. La continuación del proyecto, con la ampliación del muestreo mineralógico, permitirá sin duda profundizar en este problema histórico. 


\section{BIBLIOGRAFÍA}

Alcalde, G.; Molist, M. y Toledo, A. (1994): Procés d'ocupació de la Bauma del Serrat del Pont (la Garrotxa a partir del 1450 AC. Publicacions Eventuals d'Arqueologia de la Garrotxa, 1. Olot, Museu Comarcal de la Garrotxa.

Alcalde, G.; Molist, M.; Toledo, A.; Caravaca, J. y CoDINA, D. (1994): "La Bauma del Serrat del Pont (Tortellà, la Garrotxa), un taller de metal.lúrgia del coure d'ara fa 4.000 anys". Annals de l'Institut d'Estudis Gironins, XXXIII: 43-48.

Alcalde, G.; Molist, M.; Sana, M. y Toledo, A. (1997): Procés d'ocupació de la Bauma del Serrat del Pont (la Garrotxa) entre el 2900 i el 1450 cal. AC. Publicacions Eventuals d'Arqueologia de la Garrotxa, 2. Olot, Museu Comarcal de la Garrotxa.

Ayora, C. y CASAS, J.M. (1985): "Mineralización estratiforme de $\mathrm{Pb}-\mathrm{Zn}-\mathrm{Cu}$ en el Paleozoico de Bassegoda (Pirineo Oriental)". Acta Geológica Hispànica, 20: 233-239.

BERnABÉU, J. (1989): La tradición cultural de las cerámicas impresas en la zona oriental de la Península Ibérica. Servicio de Investigación Prehistórica. Serie de Trabajos Varios, 86. Diputación Provincial de Valencia.

Boquer, S.; Bosch, J.; Cruells, W.; Miret, J.; Molist, M. y Rodón, T. (1995): El jaciment de l'Institut de Batxillerat Antoni Pous. Un assentament a l'aire lliure de finals del calcolític (Manlleu, Osona). Monografies, 15. Generalitat de Catalunya. Barcelona.

Bosch Lloret, A. (1994): "El neolítico antiguo en el nordeste de Cataluña. Contribución a la problemática de la evolución de las primeras comunidades neolíticas en el mediterráneo occidental". Trabajos de Prehistoria, 51 (1): 55-75.

Castro, P.V.; Lull, V. y Mico, R. (1996): Cronología de la Prehistoria Reciente de la Península Ibérica y $\mathrm{Ba}$ leares (c.2800-900 cal. ANE). BAR International Series, 652. Oxford.

Denison, S. (1994): "Bronze Age in the smelting pot". British Archaeological news, 10: 6-7.

EQUiP MINFERRI (1997): “Noves dades per la caracterizació dels assentaments a l'aire lliure durant la primera meitat del II mil-lenni cal.BC: primers resultats de les excavacions en el jaciment de Minferri (Juneda, les Garrigues)". Revista d'Arqueologia de Ponent, 7: 161-204.

Fernández-Miranda, M.; Montero, I. y Rovira, S. (1995): "Los primeros objetos de bronce en el occidente de Europa". Trabajos de Prehistoria, 52 (1): 57-69.

Gattiglia, A. y Rossi, M. (1995): "Les céramiques de la mine préhistorique de Saint-Verán (Hautes-Alpes)". Bulletin de la Societé Préhistorique Française, 92 (4): 509-518.
Gómez Ramos, P. (1996a): “¿Donde están las toberas de la Edad del Bronce en la Península Ibérica?". Acontia, 2: 29-38.

- (1996b): "Hornos de reducción de cobre y bronce en la pre y protohistoria de la Península Ibérica". Trabajos de Prehistoria, 53 (1): 127-143.

Guilaine, J. (1972): L'age du Bronze en Languedoc Occidental, Rousillon et Ariege. Memoires de la Societé Préhistorique Française, 9. Paris.

HARRISON, R.J. (1988): "Bell Beakears in Spain and Portugal: working with radiocarbon dates in the $3 \mathrm{rd} \mathrm{mi-}$ llenium BC". Antiquity, 62: 464-72

Harrison, R. J.; Bubner, T. y Hibbs, V. A. (1976): “The Beaker pottery from El Acebuchal, Carmona (Prov. Sevilla)". Madrider Mitteilungen, 17: 79-141.

Llussa, A.; Gallart, J.; Ribes, J.; Costafreda, A.; NaDAL, A. y Guerrero, Ll. (1990): "El jaciment del bronze de Minferri (Juneda, Les Garrigues)". Quaderns d'Arqueologia del Grup de Recerques de "La Femosa", 5.

Martín, A. (1992): "Estrategia y culturas del Neolítico Final y Calcolítico en Cataluña". Aragón/Litoral Mediterráneo. Intercambios culturales durante la Prehistoria. Institución Fernando el Católico. Zaragoza: 389-397.

MAYA, J.L. (1992): “Calcolítico y Edad del Bronce en Catalunya". Aragón/Litoral Mediterráneo. Intercambios culturales durante la Prehistoria. Institución Fernando el Católico. Zaragoza: 551-554

Montero Ruiz, I. (1994): El Origen de la Metalurgia en el Sudeste de la Península Ibérica. Instituto de Estudios Almerienses. Colección de Investigación, 19. Almería.

MuÑoz, A.M. (1965): La cultura catalana de los 'sepulcros de fosa'. Barcelona I.A.P. Universitat de Barcilona.

Priego, Ma C. y Quero, S. (1992): El Ventorro, un poblado prehistórico de los albores de la metalurgia. Estudios de Prehistoria y Arqueología Madrileñas, 8. Madrid.

Rovira, S. y Montero, I. (1994): "Metalurgia Campaniforme y de la Edad del Bronce en la Comunidad de Madrid". En M.C. Blasco (ed.): El Horizonte Campaniforme en la Región de Madrid en el Centenario de Ciempozuelos. Patrimonio Arqueológico del Bajo Manzanares, 2. Universidad Autónoma. Madrid: 137-164.

Rovira, S.; Montero, I. y Consuegra, S. (1997): Las primeras etapas metalúrgicas en la Península Ibérica. I Análisis de materiales. Instituto Universitario Ortega y Gasset. Madrid.

SAnches, M.J. (1996): Ocupaçao Pré-histórica do Nordeste de Portugal. Fundación Rei Alfonso Henriques. Zamora.

Serra Vilaró, J. (1923): El vas campaniforme a Catalunya i les coves sepulcrals Eneolítiques. Solsona-Manresa. 
- (1924): De Metalurgia Prehistòrica a Catalunya. Museu Arqueològic Diocesà. Solsona.

Solá-Morales, J. M. (1956): "Las minas de plata de Rocabruna (Referencia histórica)". Pyrene, 58: 1.6211.631 .

Tarradell, M. (1962): Les Arrels de Catalunya. Ed. Vicens Vives. Barcelona.

Vidal, L.M. (1886): Reseña Geológica y Minera de la Provincia de Gerona. Madrid.
VILASECA, S. (1973): Reus y su entorno en la Prehistoria. Asociación de Estudios Reusenses. 2 vol. Reus.

Voruz, J.L. (1995): "Chronologie absolue de la fin du néolithique dans le bassin Rhodanien". En J. L.Voruz (ed.): Chronologies neolithiques.De 6000 à 2000 ane dans le Bassin Rhodanien. S.P.R.: 217-229.

WALDREN, W.H. (1986): The balearic pentapartite division of prehistory. British Archaeological Reports. International Series, 282. Oxford. 